OPEN ACCESS

Edited by:

Mattias K. Sköld,

Uppsala University, Sweden

Reviewed by:

Steven A. Robicsek,

University of Florida,

United States

Fredrik Clausen,

Uppsala University, Sweden

*Correspondence:

Frederick A. Zeiler

umzeiler@myumanitoba.ca

Specialty section:

This article was submitted

to Neurotrauma,

a section of the journa

Frontiers in Neurology

Received: 17 April 2017 Accepted: 23 June 2017

Published: 10 July 2017

Citation:

Zeiler FA, Thelin EP, Czosnyka M, Hutchinson PJ, Menon DK and Helmy A (2017) Cerebrospinal Fluid and Microdialysis Cytokines in Severe Traumatic Brain Injury: A Scoping Systematic Review.

Front. Neurol. 8:331.

doi: 10.3389/fneur.2017.00331

\section{Cerebrospinal Fluid and Microdialysis Cytokines in Severe Traumatic Brain Injury: A Scoping Systematic Review}

\author{
Frederick A. Zeiler,1,2,3* Eric Peter Thelin ${ }^{4,5}$, Marek Czosnyka ${ }^{4}$, Peter J. Hutchinson ${ }^{4}$, \\ David K. Menon ${ }^{3}$ and Adel Helmy
}

'Department of Surgery, Section of Neurosurgery, University of Manitoba, Winnipeg, MB, Canada, ${ }^{2}$ Clinician Investigator Program, University of Manitoba. Winnipeg, MB, Canada, ${ }^{3}$ Department of Anesthesia, Addenbrooke's Hospital, University of Cambridge, Cambridge, United Kingdom, ${ }^{4}$ Division of Neurosurgery, Department of Clinical Neurosciences, University of Cambridge, Cambridge Biomedical Campus, Cambridge, United Kingdom, ${ }^{5}$ Department of Clinical Neuroscience, Karolinska Institute, Stockholm, Sweden

Objective: To perform two scoping systematic reviews of the literature on cytokine measurement in: 1. cerebral microdialysis (CMD) and 2. cerebrospinal fluid (CSF) in severe traumatic brain injury (TBI) patients.

Methods: Two separate systematic reviews were conducted: one for CMD cytokines and the second for CSF cytokines. Both were conducted in severe TBI (STBI) patients only.

Data sources: Articles from MEDLINE, BIOSIS, EMBASE, Global Health, Scopus, Cochrane Library (inception to October 2016), reference lists of relevant articles, and gray literature were searched.

Study selection: Two reviewers independently identified all manuscripts utilizing predefined inclusion/exclusion criteria. A two-tier filter of references was conducted.

Data extraction: Patient demographic and study data were extracted to tables.

Results: There were 19 studies identified describing the analysis of cytokines via CMD in 267 sTBI patients. Similarly, there were 32 studies identified describing the analysis of CSF cytokines in 1,363 sTBI patients. The two systematic reviews demonstrated: 1. limited literature available on CMD cytokine measurement in sTBI, with some preliminary data supporting feasibility of measurement and associations between cytokines and patient outcome. 2. Various CSF measured cytokines may be associated with patient outcome at 6-12 months, including interleukin (IL)-1b, IL-1ra, IL-6, IL-8, IL-10, and tumor necrosis factor 3 . There is little to no literature in support of an association between CSF cytokines and neurophysiologic or tissue outcomes.

Conclusion: The evaluation of CMD and CSF cytokines is an emerging area of the literature in STBI. Further, large prospective multicenter studies on cytokines in CMD and CSF need to be conducted.

Keywords: cytokines, traumatic brain injury, brain injury, systematic review, microdialysis, cerebrospinal fluid 


\section{INTRODUCTION}

Neuroinflammation after traumatic brain injury (TBI) is postulated to be a key driver of secondary brain injury in the acute/ subacute phase after injury $(1,2)$. Upregulation of various components of the inflammatory cascade have been associated with lesion expansion (3), cerebral edema (4), derangements in neural transmission (5), and subsequent tissue death (6) in animal models of stroke and TBI. In humans, the inflammatory process post-TBI has been of interest, since its therapeutic modulation can potentially lead to amelioration of pathophysiology, tissue salvage, and improved patient outcomes $(7,8)$. Serum cytokine levels are easily measured in TBI patients, and elevation in pro-inflammatory cytokines have been associated with worse patient outcome $(9,10)$. However, systemic cytokine levels can be confounded by extracranial pathology and variable bloodbrain barrier leak of centrally derived mediators. Measurement of cerebral levels of cytokines provides a more direct metric of neuroinflammation following TBI, but, to date, the measurement of cerebral microdialysis (CMD) (11-29) and cerebrospinal fluid (CSF) (30-65) cytokines have been limited to small studies.

The goal of this study was to produce a scoping systematic review of the literature on both CMD and CSF cytokines in severe TBI (sTBI). Our hope was to produce a comprehensive overview of the literature on this emerging topic.

\section{METHODS}

Two separate scoping systematic reviews were conducted, using the methodology outlined in the Cochrane Handbook for Systematic Reviewers (66). Data were reported following the preferred reporting items for systematic reviews and meta-analyses (67). The review questions and search strategy were decided upon by the primary author (Frederick A. Zeiler) and supervisors (Adel Helmy and David K. Menon).

This manuscript was conducted in concert with a similar review on cytokines in CMD and CSF for aneurysmal subarachnoid hemorrhage (SAH) patients.

\section{Search Question and Population of Interest}

Given that two separate systematic reviews were conducted, one for CMD cytokines and the other for CSF cytokines, two distinct questions were posed. The limited literature on CMD cytokines identified through a preliminary search of PubMed led us to conduct a scoping review for the CMD cytokine search. We attempted to identify all studies in this area to date, and all articles describing microdialysis cytokine measures in humans with sTBI included in our review in order to provide a comprehensive overview of this emerging area of literature. The key question for this part of the review was:

- What literature has been published on CMD of cytokines in sTBI?

The larger literature base for CSF cytokines in TBI led us to narrow our question for this scoping review, focusing on relevant outcomes (see below). The questions posed for this scoping systematic review was:
- Is there literature to suggest an association between CSF cytokine measures in STBI and patient outcome, neurophysiologic outcome, or tissue outcome?

For the CSF cytokine review, the primary outcome measures were documented association between CSF cytokine levels and: patient outcome, neurophysiologic outcome (as measured via intensive care unit (ICU)-based monitoring; intracranial pressure (ICP)/cerebral perfusion pressure (CPP), brain tissue oxygen monitoring $\left(\mathrm{PbtO}_{2}\right)$, thermal diffusion assessment of cerebral blood flow (CBF), transcranial Doppler (TCD) measure of cerebral blood flow velocity (CBFV), any neuroimaging based assessment of $\mathrm{CBF} /$ perfusion, and electrophysiology), and tissue outcome [as assessed on follow-up neuroimaging by either computed tomography (CT) or magnetic resonance imaging]. Any outcome score or mention of morbidity/mortality within the studies was deemed acceptable for documentation of patient outcome. Secondary outcome measures were complications associated with CSF monitoring of cytokines.

The list of included cytokines in CMD or CSF included: interleukin (IL)-1a, IL-1b, IL-1ra, IL-2, sIL-2ra, IL-3, IL-4, IL-5, IL-6, IL-7, IL-8, IL-9, IL-10, IL-11, IL-12, IL-12p70, IL-13, IL-14, IL-15, IL-16, IL-17, inducible protein (IP)-10, eotaxin, tumor necrosis factor (TNF), interferon gamma (INF-g), monocyte chemoattractant proteins, macrophage inflammatory proteins (MIPs), transforming growth factor (TGF), nerve growth factor (NGF), brain-derived neurotrophic factor, glial-derived neurotrophic factor, soluble tumor necrosis factor receptor (sTNFR), granulocyte macrophage colony stimulating factor, soluble FAS, soluble vascular cell adhesion molecule (sVCAM)-1, and soluble intracellular adhesion molecule (sICAM)-1, platelet-derived growth factor, regulated on activation, normal $\mathrm{T}$ cell expressed and secreted (RANTES), macrophage-derived chemokine (MDC), fms-like tyrosine kinase 3 (Flt3), Fractalkine, and fibroblast growth factor receptor.

\section{Inclusion/Exclusion Criteria CMD Cytokine Review}

Inclusion criteria were: all studies including human subjects with sTBI (GCS 8 or less), any study size, any age category, CMD analysis for cytokines, and mention of any outcome (patient based or otherwise). Exclusion criteria were: non-English studies and animal studies.

\section{CSF Cytokine Review}

Inclusion criteria were: all studies including human subjects with sTBI (GCS of 8 or less), studies with 10 or more patients, any age category, CSF analysis for cytokines, and documentation either: patient functional outcome, neurophysiologic outcome, or tissue outcome in relation to CSF cytokine measures. Exclusion criteria were: non-English studies, animal studies, and studies of less than 10 patients. Non-English studies were excluded given the small number identified.

\section{Search Strategies}

MEDLINE, BIOSIS, EMBASE, Global Health, SCOPUS, and Cochrane Library from inception to October 2016 were searched 
using individualized search strategies. The search strategy for the CMD scoping systematic review using MEDLINE can be seen in Appendix A in Supplementary Material, with a similar search strategy utilized for the other databases. Further, the search strategy for the CSF scoping systematic review using MEDLINE can be seen in Appendix B in Supplementary Material, with similar strategies employed for the other databases.

In addition, we surveyed relevant meeting proceedings for the last 5 years looking for ongoing and unpublished work based on cytokine analysis via CMD or CSF in sTBI patients. The meeting proceedings of the following professional societies were searched: Canadian Neurological Sciences Federation, American Association of Neurological Surgeons, Congress of Neurological Surgeons, European Neurosurgical Society, World Federation of Neurological Surgeons, National Neurotrauma Society, American Neurology Association, American Academy of Neurology, European Federation of Neurological Science, World Congress of Neurology, Society of Critical Care Medicine, Neurocritical Care Society, European Society for Intensive Care Medicine, World Federation of Societies of Intensive and Critical Care Medicine, American Society for Anesthesiologists, World Federation of Societies of Anesthesiologist, Australian Society of Anesthesiologists, International Anesthesia Research Society, Society of Neurosurgical Anesthesiology and Critical Care, Society for Neuroscience in Anesthesiology and Critical Care, Japanese Society of Neuroanesthesia and Critical Care, International NeuroTrauma Society, International Brain Injury Association, and the College of Intensive Care Medicine Annual Scientific Meeting (CICMASM-Australia).

Finally, reference lists of any review articles on CSF or CMD cytokines were reviewed for any missed relevant studies.

\section{Study Selection}

Utilizing two reviewers, a two-step review of all articles returned by our search strategies was performed. First, the reviewers independently (Frederick A. Zeiler and Eric Peter Thelin) screened titles and abstracts of the returned articles to decide if they met the inclusion criteria. Second, full text of the chosen articles was then assessed to confirm if they met the inclusion criteria and that the primary outcomes of interest were reported in the study (Frederick A. Zeiler and Eric Peter Thelin). Any discrepancies between the two reviewers were resolved by a third reviewer if needed (Adel Helmy or David K. Menon).

\section{Data Collection}

Data were extracted from the selected articles and stored in an electronic database. Data fields included: patient demographics, type of study, article location, number of patients, CMD/CSF substrate measured, CMD/CSF measurement details (probe tissue location, sampling frequency), outcome measure described (patient, neurophysiologic, tissue), association between CMD/ CSF cytokine measure to outcome, and complications. All extracted data can be found in Tables 1 through 4, with study designs in Tables 1 and 2, and study outcomes in Tables 3 and 4.

\section{Bias Assessment}

As the goal of this review was to produce a systematically conducted scoping review of the available literature on CMD and
CSF cytokine measures in sTBI, formal bias assessment was not done. Our desire was to produce a comprehensive overview of the current literature on the topic of CMD/CSF cytokines in sTBI. Formal evidence grading was not conducted (given the limited and heterogenous literature body), and thus we deemed formal bias risk assessment unnecessary for this emerging area of literature, which clearly suffers from standard biases associated with new areas of clinical research.

\section{Statistical Analysis}

A meta-analysis was not performed in this study due to the heterogeneity of data and study design within the articles identified.

\section{RESULTS}

\section{Search Strategy Results CMD Cytokine Search}

Results of the search strategy for CMD cytokines in sTBI is shown in the flow diagram in Figure 1. In total, 259 articles were identified, with 255 from the database and 4 from meeting proceeding sources. After removal of the duplicates, there were 144 articles left for assessment in the first filter of title and abstract. Thirty-seven articles passed the first filter, requiring acquisition of the full manuscript to assess inclusion eligibility. After assessing the full manuscripts, 19 articles were deemed eligible for final inclusion in the scoping systematic review. No articles were added from the reference sections of either review papers or the parent manuscripts included in the systematic review.

\section{CSF Cytokine Search}

The search strategy flow diagram for the CSF cytokine scoping systematic review is shown in Figure 2. Overall, 3,218 articles were identified, with 3,214 from the database search and 4 from published meeting proceedings. There were 1,317 duplicates removed, leaving 1,901 references to review in the first filter. Applying the inclusion/exclusion criteria to the title and abstract of these articles, 105 manuscripts were selected for review of the full article. One additional reference was added from the reference sections of review papers. During the second filter of the full manuscript, 36 met the final inclusion criteria for the scoping systematic review. Remaining articles were excluded due to non-relevance.

\section{Patient/Study Demographics CDM Cytokine Review}

Of the 19 articles included in the CMD cytokine portion of the systematic review (11-19), 15 were formal manuscript publications $(14-24,26-29)$ and 4 were meeting abstract publications $(11-13,25)$. There were 13 prospective studies $(13-16,18-21$, 25-29), with 12 prospective observational studies (13-15, 18-21, 25-29) and 1 prospective randomized control trial (16). Four studies were retrospective case series or database reviews $(11,20$, $22,23)$. Finally, two studies were of "unknown" study design given a lack of information available within the methods $(12,24)$.

The study population described in CMD cytokine papers was generally poorly characterized sTBI patient populations, undergoing various ICU and surgical therapies for their heterogeneous 
TABLE 1 | CMD cytokine study characteristics and patient demographics.

\begin{tabular}{|c|c|c|c|c|c|c|}
\hline Reference & $\begin{array}{l}\text { Number of } \\
\text { patients }\end{array}$ & Study type & $\begin{array}{l}\text { Article } \\
\text { location }\end{array}$ & $\begin{array}{l}\text { Mean age } \\
\text { (years) }\end{array}$ & $\begin{array}{l}\text { Patient } \\
\text { characteristics }\end{array}$ & Primary and secondary goal of study \\
\hline \multirow[t]{2}{*}{ Cederberg et al. (11) } & 7 & $\begin{array}{l}\text { Retrospective } \\
\text { case series }\end{array}$ & $\begin{array}{l}\text { Meeting } \\
\text { abstract }\end{array}$ & $\begin{array}{l}\text { Unknown } \\
\text { "children" }\end{array}$ & $\begin{array}{l}\text { Severe TBI; } 3 \\
\text { underwent DC }\end{array}$ & $\begin{array}{l}\text { Primary: to compare CMD cytokines to } \\
\text { common } \mathrm{CMD} \text { measures, } \mathrm{PbtO}_{2} \text {, and ICP }\end{array}$ \\
\hline & & & & & & Secondary: none mentioned \\
\hline \multirow[t]{2}{*}{ Figaji et al. (12) } & 5 & Unknown & $\begin{array}{l}\text { Meeting } \\
\text { abstract }\end{array}$ & $\begin{array}{l}\text { Unknown } \\
\text { "children" }\end{array}$ & Severe TBI & $\begin{array}{l}\text { Primary: to compare CMD cytokine and other } \\
\text { CMD measures }\end{array}$ \\
\hline & & & & & & Secondary: none mentioned \\
\hline \multirow[t]{2}{*}{ Guilfoyle et al. (13) } & 12 & $\begin{array}{l}\text { Prospective } \\
\text { observational }\end{array}$ & $\begin{array}{l}\text { Meeting } \\
\text { abstract }\end{array}$ & $\begin{array}{l}\text { Unknown } \\
\text { "adults" }\end{array}$ & Severe TBI & $\begin{array}{l}\text { Primary: to compared CMD cytokine } \\
\text { measures in healthy vs. peri-lesional tissue }\end{array}$ \\
\hline & & & & & & Secondary: none mentioned \\
\hline \multirow[t]{2}{*}{ aHelmy et al. (14) } & 12 & $\begin{array}{l}\text { Prospective } \\
\text { observational }\end{array}$ & Manuscript & $\begin{array}{l}\text { Unknown } \\
\text { "adults" }\end{array}$ & Severe TBI & $\begin{array}{l}\text { Primary: to perform a principle component } \\
\text { analysis of CMD cytokines to determine } \\
\text { cytokine patterns and temporal profiles }\end{array}$ \\
\hline & & & & & & Secondary: none mentioned \\
\hline \multirow[t]{2}{*}{ aHelmy et al. (15) } & 12 & $\begin{array}{l}\text { Prospective } \\
\text { observational }\end{array}$ & Manuscript & $\begin{array}{l}\text { Unknown } \\
\text { "adults" }\end{array}$ & Severe TBI & $\begin{array}{l}\text { Primary: } 1 \text {. To compare crystalloid vs. albumin } \\
\text { perfusate in CMD cytokine recovery. } \\
\text { 2. To compare the cytokine profile in sTBI }\end{array}$ \\
\hline & & & & & & Secondary: not specified \\
\hline \multirow[t]{3}{*}{ bHelmy et al. (16) } & 20 & Prospective RCT & Manuscript & $\begin{array}{l}38.9 \text { years } \\
\text { (range: }\end{array}$ & $\begin{array}{l}\text { Severe diffuse } \\
\text { TBI; randomized }\end{array}$ & $\begin{array}{l}\text { Primary: } 1 . \text { To provide safety data in a } \\
\text { randomized fashion on rhlL-1ra in STBI }\end{array}$ \\
\hline & & & & 18-61 years) & $\begin{array}{l}\text { to subcutaneous } \\
\text { rhlL-1ra }\end{array}$ & $\begin{array}{l}\text { 2. To describe the impact of rhlL-1ra on } \\
\text { CMD cytokine profiles }\end{array}$ \\
\hline & & & & & & Secondary: none mentioned \\
\hline \multirow[t]{2}{*}{ bHelmy et al. (17) } & 20 & $\begin{array}{l}\text { Retrospective } \\
\text { database analysis }\end{array}$ & Manuscript & $\begin{array}{l}38.9 \text { years } \\
\text { (range: } \\
\text { 18-61 years) }\end{array}$ & $\begin{array}{l}\text { Severe diffuse } \\
\text { TBI; randomized } \\
\text { to subcutaneous }\end{array}$ & $\begin{array}{l}\text { Primary: to retrospectively analyze RCT data } \\
\text { on rhlL-1ra administration, to better delineate } \\
\text { the temporal change in cytokine profiles }\end{array}$ \\
\hline & & & & & rhlL-1ra & Secondary: none mentioned \\
\hline \multirow[t]{2}{*}{ Hillman et al. (18) } & $\begin{array}{l}9 \text { (10 total, but } \\
\text { failed CMD } \\
\text { catheter in 1) }\end{array}$ & $\begin{array}{l}\text { Prospective } \\
\text { observational }\end{array}$ & Manuscript & Unknown & $\begin{array}{l}\text { Severe brain injury } \\
\text { (undisclosed } \\
\text { number of aSAH } \\
\text { and sTBI patients) }\end{array}$ & $\begin{array}{l}\text { Primary: to evaluate newer microdialysis } \\
\text { catheters and their ability to measure various } \\
\text { CMD macromolecules (including IL-6) vs. older } \\
\text { catheters. Varied perfusates were also analyzed }\end{array}$ \\
\hline & & & & & & Secondary: none mentioned \\
\hline \multirow[t]{2}{*}{ Hillman et al. (19) } & $\begin{array}{l}7 \text { with } \mathrm{TBI}(14 \\
\text { total; mixed }\end{array}$ & $\begin{array}{l}\text { Prospective } \\
\text { observational }\end{array}$ & Manuscript & Unknown & $\begin{array}{l}\text { sTBI-5 } \\
\text { requiring "surgery" }\end{array}$ & $\begin{array}{l}\text { Primary: to determine the CMD cytokine } \\
\text { patterns in } \mathrm{TBI}\end{array}$ \\
\hline & injury sources) & & & & & Secondary: none mentioned \\
\hline \multirow[t]{2}{*}{ Hutchinson et al. (20) } & 15 & $\begin{array}{l}\text { Prospective } \\
\text { observational }\end{array}$ & Manuscript & $\begin{array}{l}41 \text { years } \\
\text { (range: }\end{array}$ & Severe TBI & $\begin{array}{l}\text { Primary: to determine the feasibility of measures } \\
\mathrm{IL}-1 \mathrm{a}, \mathrm{IL}-1 \mathrm{~b} \text {, and IL-1ra in CMD samples }\end{array}$ \\
\hline & & & & 17-68 years) & & $\begin{array}{l}\text { Secondary: correlation of cytokine to ICP, CPP, } \\
\text { and patient outcome }\end{array}$ \\
\hline \multirow[t]{2}{*}{ Mellergard et al. (21) } & $\begin{array}{l}7 \text { (total } 38 \\
\text { patients; only }\end{array}$ & $\begin{array}{l}\text { Prospective } \\
\text { observational }\end{array}$ & Manuscript & Unknown & Severe TBI & $\begin{array}{l}\text { Primary: to evaluate CMD cytokine profiles } \\
\text { immediately after insertion of the CMD catheter }\end{array}$ \\
\hline & 7 with $\mathrm{TBI})$ & & & & & Secondary: none mentioned \\
\hline \multirow[t]{2}{*}{ 'Mellergard et al. (22) } & $\begin{array}{l}57 \text { (total } 145 \\
\text { patients; only }\end{array}$ & $\begin{array}{l}\text { Retrospective } \\
\text { case series }\end{array}$ & Manuscript & Unknown & Severe TBI & $\begin{array}{l}\text { Primary: to determine the CMD cytokine } \\
\text { responds to } \mathrm{TBI}\end{array}$ \\
\hline & 57 with TBI) & & & & & Secondary: none mentioned \\
\hline \multirow[t]{2}{*}{ 'Mellergard et al. (23) } & $\begin{array}{l}57 \text { (total } 145 \\
\text { patients; only }\end{array}$ & $\begin{array}{l}\text { Retrospective } \\
\text { case series }\end{array}$ & Manuscript & Unknown & Severe TBI & $\begin{array}{l}\text { Primary: to determine the CMD cytokine } \\
\text { responds to TBI }\end{array}$ \\
\hline & 57 with TBI) & & & & & Secondary: none mentioned \\
\hline \multirow[t]{2}{*}{ Mellergard et al. (24) } & 69 & Unknown & Manuscript & $\begin{array}{l}45.9 \text { years } \\
\text { (range: }\end{array}$ & Severe TBI & $\begin{array}{l}\text { Primary: to determine if there is age-related } \\
\text { difference in CMD cytokines }\end{array}$ \\
\hline & & & & unknown) & & Secondary: none mentioned \\
\hline \multirow[t]{2}{*}{ Mondello et al. (25) } & 6 & $\begin{array}{l}\text { Prospective } \\
\text { observational }\end{array}$ & $\begin{array}{l}\text { Meeting } \\
\text { abstract }\end{array}$ & Unknown & Severe TBI & $\begin{array}{l}\text { Primary: to evaluate the temporal profile } \\
\text { of CMD and CSF cytokines in TBI }\end{array}$ \\
\hline & & & & & & Secondary: none mentioned \\
\hline
\end{tabular}


TABLE 1 | Continued

\begin{tabular}{|c|c|c|c|c|c|c|}
\hline Reference & $\begin{array}{c}\text { Number of } \\
\text { patients }\end{array}$ & Study type & $\begin{array}{l}\text { Article } \\
\text { location }\end{array}$ & $\begin{array}{l}\text { Mean age } \\
\text { (years) }\end{array}$ & $\begin{array}{l}\text { Patient } \\
\text { characteristics }\end{array}$ & Primary and secondary goal of study \\
\hline \multirow[t]{2}{*}{$\begin{array}{l}\text { Parez-Barcena } \\
\text { et al. (26) }\end{array}$} & \multirow[t]{2}{*}{16} & \multirow[t]{2}{*}{$\begin{array}{l}\text { Prospective } \\
\text { observational }\end{array}$} & \multirow[t]{2}{*}{ Manuscript } & \multirow{2}{*}{$\begin{array}{l}31.8 \text { years } \\
\text { (range: } \\
\text { 16-65 years) }\end{array}$} & \multirow[t]{2}{*}{ Severe diffuse $\mathrm{TBI}$} & $\begin{array}{l}\text { Primary: to determine the cytokine profiles } \\
\text { in severe diffuse TBI patients }\end{array}$ \\
\hline & & & & & & $\begin{array}{l}\text { Secondary: to determine the correlation between } \\
\text { cytokines and ICP, } \mathrm{PbtO}_{2} \text {, and CT changes }\end{array}$ \\
\hline \multirow[t]{2}{*}{ Roberts et al. (27) } & \multirow[t]{2}{*}{8} & \multirow[t]{2}{*}{$\begin{array}{l}\text { Prospective } \\
\text { observational }\end{array}$} & \multirow[t]{2}{*}{ Manuscript } & \multirow{2}{*}{$\begin{array}{l}43.4 \text { years } \\
\text { (range: } \\
\text { unknown) }\end{array}$} & \multirow[t]{2}{*}{ Severe TBI } & $\begin{array}{l}\text { Primary: to measure the blood/CSF/CMD MMP } \\
\text { and cytokine response post-TBI }\end{array}$ \\
\hline & & & & & & $\begin{array}{l}\text { Secondary: correlation to neurologic exam, ICP, } \\
\mathrm{PbtO}_{2}, \mathrm{GOS} \text { at discharge }\end{array}$ \\
\hline \multirow[t]{2}{*}{ Winter et al. (28) } & \multirow[t]{2}{*}{3} & \multirow[t]{2}{*}{$\begin{array}{l}\text { Prospective } \\
\text { observational }\end{array}$} & \multirow[t]{2}{*}{ Manuscript } & \multirow[t]{2}{*}{ Unknown } & \multirow[t]{2}{*}{ Severe TBI } & $\begin{array}{l}\text { Primary: to describe the technique of cytokine } \\
\text { measurement via CMD }\end{array}$ \\
\hline & & & & & & Secondary: describe cytokine patterns in TBI \\
\hline \multirow[t]{2}{*}{ Winter et al. (29) } & \multirow[t]{2}{*}{14} & \multirow[t]{2}{*}{$\begin{array}{l}\text { Prospective } \\
\text { observational }\end{array}$} & \multirow[t]{2}{*}{ Manuscript } & \multirow{2}{*}{$\begin{array}{l}43.1 \text { years } \\
\text { (range: } \\
21-77 \text { years) }\end{array}$} & \multirow[t]{2}{*}{ Severe TBI } & $\begin{array}{l}\text { Primary: to evaluate the changes in CMD } \\
\text { cytokines post-TBI }\end{array}$ \\
\hline & & & & & & Secondary: correlation to patient outcome \\
\hline
\end{tabular}

TBI, traumatic brain injury; STBI, severe TBI; aSAH, aneurysmal subarachnoid hemorrhage; DC, decompressive craniectomy; CMD, cerebral microdialysis; RCT, randomized control trial; ICP, intracranial pressure; CPP, cerebral perfusion pressure; CSF, cerebrospinal fluid; $L P R$, lactate:pyruvate ratio; CT, computed tomography; PbtO ${ }_{2}$, partial pressure of oxygen in brain tissue; MMPs, matrix metalloproteins, IL, interleukin; $a$, alpha; $b$, beta; ra, receptor anatogonist; rh, recombinant human.

aSame patient population reported in both Helmy et al. (14) and Helmy et al. (15).

'Same patient population described in Helmy et al. (16) and Helmy et al. (17).

'Same patient population reported in both Mellergard et al. (22) and Mellergard et al. (23).

intracranial pathology $(11-15,18-25,27-29)$. Three studies focused on only those patients with imaging defined "diffuse" brain injury, without extra-axial or large focal intraparenchymal lesions $(16,17,26)$.

A total of 267 unique patients with sTBI were described across the 19 studies included in the CMD cytokine review. Thirty-six patients were "diffuse" sTBI only $(16,17,26)$, with the remaining being unspecified heterogeneous sTBI pathology. We believe that some of the studies included within this portion of the review may contain duplicate patient information, as marked in Tables 1 and 3. Multiple publications from the same research groups likely were conducted on the same patient populations, yielding unique and separate manuscripts on the same group of patients. Though we must acknowledge it was difficult to determine, in some circumstances, whether CMD cytokine analysis was being conducted on new patient groups or existing banked samples from previous prospective studies. With that said, our goal for the CMD cytokine scoping review was to provide an overview of all available literature in the area, hence we have included all published papers on CMD cytokines in STBI within this review.

\section{CSF Cytokine Review}

Of the 36 articles included in the CSF cytokine systematic review (20-65), 32 were formal manuscript publications (30-36, 39, 40, 42-61, 63-65) and 4 were meeting abstract publications (37, 38, $41,62)$. There were 34 prospective studies, all being observational studies $(30-61,64,65)$. One study was a retrospective case series (63). Finally, one study had insufficient information to determine the design (62).

The populations described with in the CSF cytokine studies were almost all sTBI patients with unspecified heterogeneous injury patterns. Three studies documented the inclusion of both moderate-severe patients within the methods $(39,53,62)$. We were unable to separate the moderate and sTBI patients within these studies, hence they were all included in the final descriptive statistics.

A total of 1,363 patients were described across all studies included in the CSF cytokine systematic review. The mean age for each study cohort varied significantly across studies. Twenty-one studies included pediatric patients within their studies, either as the primary population of interest or included with adult patients (31-35, 42, 44, 47-50, 52, 54, 55, 57, 59, 60, 63-65). Therapies received by these patients while in the ICU varied significantly, with profound heterogeneity in treatment provided. Details surrounding patient cohort, study design, and concurrent therapies can be found in Tables 2 and $\mathbf{4}$. We made substantial efforts to exclude duplicate patient data across studies. However, given that many of the papers came from centers of excellence for TBI research, some of the patient data may be cross reported in multiple studies. This could reduce the total overall number of unique patients. It was impossible based on the information provided within the parent studies to tease out all patients which were reported more than once.

\section{Cytokine Measurement Technique CMD Cytokine Review}

Location of the CMD catheter was the following: mixed healthy/ peri-lesional tissue in six studies $(11,13,15,21-23)$, peri-lesional in six studies $(14,16-19,28)$, healthy tissue in two studies $(27,29)$, and unknown tissue location in five studies $(12,20$, 24-26). Some studies utilized paired microdialysis catheters, one in healthy and one in peri-lesional tissue $(13,15,22,23)$. One study evaluated two catheters in one location (18). Analysis interval for CMD samples was as follows: every $6 \mathrm{~h}$ in 12 studies $(14-24,27)$, every $8 \mathrm{~h}$ in 1 study (26), every $3 \mathrm{~h}$ in 2 studies $(28,29)$, and unspecified in 4 studies $(11-13,25)$. The duration 
TABLE 2 | CSF cytokine study characteristics and patient demographics.

\begin{tabular}{|c|c|c|c|c|c|c|}
\hline Reference & $\begin{array}{l}\text { Number of } \\
\text { patients }\end{array}$ & Study type & $\begin{array}{l}\text { Article } \\
\text { location }\end{array}$ & $\begin{array}{l}\text { Mean age } \\
\text { (years) }\end{array}$ & $\begin{array}{l}\text { Patient } \\
\text { characteristics }\end{array}$ & Primary and secondary goal of study \\
\hline \multicolumn{7}{|c|}{ Patient functional outcome } \\
\hline \multirow[t]{2}{*}{ Abboud et al. (30) } & 31 & $\begin{array}{l}\text { Prospective } \\
\text { observational }\end{array}$ & Manuscript & $\begin{array}{l}31.6 \text { years (range: } \\
\text { unknown) }\end{array}$ & Severe TBI & $\begin{array}{l}\text { Primary: to describe the correlation between CSF } \\
\text { cytokine profiles and outcome at } 6 \text { and } 12 \text { months }\end{array}$ \\
\hline & & & & & & Secondary: none mentioned \\
\hline \multirow[t]{2}{*}{ Bell et al. (31) } & 15 & $\begin{array}{l}\text { Prospective } \\
\text { observational }\end{array}$ & Manuscript & $\begin{array}{l}6.1 \text { years (range: } \\
0.1-16 \text { years) }\end{array}$ & Severe TBI & $\begin{array}{l}\text { Primary: to determine the relationship between } \\
\text { IL-6 and IL-10 with patient outcome }\end{array}$ \\
\hline & & & & & & $\begin{array}{l}\text { Secondary: to compare CSF cytokine levels to } \\
\text { non-TBI control subjects }(n=20)\end{array}$ \\
\hline \multirow[t]{2}{*}{ Chiaretti et al. (32) } & 29 & $\begin{array}{l}\text { Prospective } \\
\text { observational }\end{array}$ & Manuscript & $\begin{array}{l}9.7 \text { years (range: } \\
1.3-15.6 \text { years) }\end{array}$ & Severe TBI & $\begin{array}{l}\text { Primary: to determine the association between } \\
\text { IL-6 and patient outcome }\end{array}$ \\
\hline & & & & & & $\begin{array}{l}\text { Secondary: to determine the correlation between IL-6 } \\
\text { and NGF in CSF. Also to compare to non-TBI control } \\
\text { patients }(n=31)\end{array}$ \\
\hline \multirow[t]{2}{*}{ Chiaretti et al. (33) } & 27 & $\begin{array}{l}\text { Prospective } \\
\text { observational }\end{array}$ & Manuscript & $\begin{array}{l}8.6 \text { years (range: } \\
1.3-15.6)\end{array}$ & Severe TBI & $\begin{array}{l}\text { Primary: to determine the association between IL-1b, } \\
\mathrm{IL}-6, \mathrm{NGF}, \mathrm{BDNF} \text {, and GDNF with patient outcome }\end{array}$ \\
\hline & & & & & & Secondary: none mentioned \\
\hline \multirow[t]{2}{*}{ Chiaretti et al. (34) } & 14 & $\begin{array}{l}\text { Prospective } \\
\text { observational }\end{array}$ & Manuscript & $\begin{array}{l}7.8 \text { years (range: } \\
0.3-15.6 \text { years) }\end{array}$ & Severe TBI & $\begin{array}{l}\text { Primary: to determine the relationship between } \\
\mathrm{IL}-1 \mathrm{~b} \text { and IL- } 6 \text { with patient outcome }\end{array}$ \\
\hline & & & & & & $\begin{array}{l}\text { Secondary: to compared cytokine expression } \\
\text { to obstructive hydrocephalus controls }\end{array}$ \\
\hline \multirow[t]{2}{*}{ Hans et al. (35) } & 11 & $\begin{array}{l}\text { Prospective } \\
\text { observational }\end{array}$ & Manuscript & $\begin{array}{l}36.7 \text { years (range: } \\
16-67)\end{array}$ & Severe TBI & $\begin{array}{l}\text { Primary: to determine the association between } \\
\text { IL-6 and sIL-6R to patient outcome }\end{array}$ \\
\hline & & & & & & $\begin{array}{l}\text { Secondary: to compare these CSF cytokine } \\
\text { levels to those in plasma }\end{array}$ \\
\hline \multirow[t]{2}{*}{ Hayakata et al. (36) } & 53 & $\begin{array}{l}\text { Prospective } \\
\text { observational }\end{array}$ & Manuscript & $34-49$ years & Severe TBI & $\begin{array}{l}\text { Primary: to determine the association between TNF-a, } \\
\mathrm{IL}-1, \mathrm{IL}-6, \mathrm{IL}-8 \text {, and IL-10 with patient outcome }\end{array}$ \\
\hline & & & & & & $\begin{array}{l}\text { Secondary: to determine the association between } \\
\text { cytokines and S100B expression in CSF. Also } \\
\text { compare cytokines to ICP }\end{array}$ \\
\hline \multirow[t]{2}{*}{ Jamil et al. (37) } & 61 & $\begin{array}{l}\text { Prospective } \\
\text { observational }\end{array}$ & $\begin{array}{l}\text { Meeting } \\
\text { abstract }\end{array}$ & Unknown "adults" & Severe TBI & $\begin{array}{l}\text { Primary: to determine the relationship between } \\
\text { acute measures of CSF cytokines and PTD at } \\
6 \text { and } 12 \text { months }\end{array}$ \\
\hline & & & & & & Secondary: none mentioned \\
\hline \multirow[t]{2}{*}{ Juengst et al. (38) } & 25 & $\begin{array}{l}\text { Prospective } \\
\text { observational }\end{array}$ & $\begin{array}{l}\text { Meeting } \\
\text { abstract }\end{array}$ & Unknown "adults" & Severe TBI & $\begin{array}{l}\text { Primary: to determine the association between } \\
\text { acute cytokine levels and apathy at } 6 \text { and } 12 \text { months } \\
\text { post-injury }\end{array}$ \\
\hline & & & & & & Secondary: none mentioned \\
\hline \multirow[t]{2}{*}{ Juengst et al. (39) } & 37 & $\begin{array}{l}\text { Prospective } \\
\text { observational }\end{array}$ & Manuscript & "Adults" & $\begin{array}{l}\text { Moderate-severe } \\
\text { TBI }\end{array}$ & $\begin{array}{l}\text { Primary: to determine the relationship between } \\
\text { TNF-a and disinhibition/suicidality post-TBI }\end{array}$ \\
\hline & & & & $\begin{array}{l}\text { Unclear overall } \\
\text { mean age }\end{array}$ & & $\begin{array}{l}\text { Secondary: compare levels in CSF and serum to } \\
\text { healthy controls }(n=15)\end{array}$ \\
\hline \multirow[t]{2}{*}{ Juengst et al. (40) } & 50 & $\begin{array}{l}\text { Prospective } \\
\text { observational }\end{array}$ & Manuscript & $\begin{array}{l}31.3 \text { years (range: } \\
\text { unknown) }\end{array}$ & Severe TBI & $\begin{array}{l}\text { Primary: to determine the relationship between acute } \\
\text { CSF cytokine profiles and the risk of PTD at } 6 \text { and } \\
12 \text { months post-injury }\end{array}$ \\
\hline & & & & & & Secondary: none mentioned \\
\hline \multirow[t]{2}{*}{ Kirchhoff et al. (41) } & 23 & $\begin{array}{l}\text { Prospective } \\
\text { observational }\end{array}$ & $\begin{array}{l}\text { Meeting } \\
\text { abstract }\end{array}$ & Unknown & Severe TBI & $\begin{array}{l}\text { Primary: to determine the IL-10 response in CSF in TBI } \\
\text { patients. Also determine the relationship to outcome. }\end{array}$ \\
\hline & & & & & & $\begin{array}{l}\text { Secondary: compared CSF in TBI to elective surgical } \\
\text { patients }(n=10)\end{array}$ \\
\hline \multirow[t]{2}{*}{ Kossmann et al. (42) } & 22 & $\begin{array}{l}\text { Prospective } \\
\text { observational }\end{array}$ & Manuscript & $\begin{array}{l}41 \text { years (range: } \\
17-73)\end{array}$ & Severe TBI & $\begin{array}{l}\text { Primary: to determine the relationship between CSF } \\
\text { IL-6 and NGF. Also determine the association to } \\
\text { patient outcome. }\end{array}$ \\
\hline & & & & & & Secondary: compare IL-6 and NGF in controls $(n=3)$ \\
\hline
\end{tabular}


TABLE 2 | Continued

\begin{tabular}{|c|c|c|c|c|c|c|}
\hline Reference & $\begin{array}{l}\text { Number of } \\
\text { patients }\end{array}$ & Study type & $\begin{array}{l}\text { Article } \\
\text { location }\end{array}$ & $\begin{array}{l}\text { Mean age } \\
\text { (years) }\end{array}$ & $\begin{array}{l}\text { Patient } \\
\text { characteristics }\end{array}$ & Primary and secondary goal of study \\
\hline \multirow[t]{2}{*}{ Kumar et al. (43) } & 114 & $\begin{array}{l}\text { Prospective } \\
\text { observational }\end{array}$ & Manuscript & $\begin{array}{l}\text { Unclear overall } \\
\text { mean age }\end{array}$ & Severe TBI & $\begin{array}{l}\text { Primary: to determine the relationship of IL- } 6 \text { in CSF to } \\
\text { serum values and patient outcome }\end{array}$ \\
\hline & & & & & & $\begin{array}{l}\text { Secondary: compare CSF levels in non-TBI controls } \\
(n=23)\end{array}$ \\
\hline \multirow[t]{2}{*}{ Kumar et al. (44) } & 111 & $\begin{array}{l}\text { Prospective } \\
\text { observational }\end{array}$ & Manuscript & $\begin{array}{l}\text { Unknown (range: } \\
16-75)\end{array}$ & Severe TBI & $\begin{array}{l}\text { Primary: to utilize PCA to determine clusters of } \\
\text { cytokines associated with patient outcome }\end{array}$ \\
\hline & & & & & & $\begin{array}{l}\text { Secondary: to determine a temporal patter of cytokine } \\
\text { clusters and relationship to outcome }\end{array}$ \\
\hline \multirow[t]{2}{*}{ Kushi et al. (45) } & 22 & $\begin{array}{l}\text { Prospective } \\
\text { observational }\end{array}$ & Manuscript & $\begin{array}{l}45 \text { years (range: } \\
\text { unknown) }\end{array}$ & Severe TBI & $\begin{array}{l}\text { Primary: to compare CSF and Serum IL-6/IL-8 } \\
\text { levels and determine the association to patient } \\
\text { outcome }\end{array}$ \\
\hline & & & & & & Secondary: none mentioned \\
\hline
\end{tabular}

\begin{tabular}{lcllll}
\hline Nwachuku et al. (46) & 32 & $\begin{array}{l}\text { Prospective } \\
\text { observational }\end{array}$ & Manuscript & $\begin{array}{l}31 \text { years (range: } \\
\text { unknown) }\end{array}$ & Severe TBI \\
\hline Santarseiri et al. (47) & 91 & $\begin{array}{l}\text { Prospective } \\
\text { observational }\end{array}$ & Manuscript & $\begin{array}{l}35.8 \text { years (range: } \\
16-73)\end{array}$ & Severe TBI
\end{tabular}

Primary: to determine the association between various CSF cytokines and patient outcome

Secondary: none mentioned

Primary: to identify CSF cytokines associated with patient outcome. Also determine association between cytokines and neuroendocrine cortisol function

Secondary: none mentioned

\begin{tabular}{|c|c|c|c|c|c|}
\hline Shiozaki et al. (48) & 35 & $\begin{array}{l}\text { Prospective } \\
\text { observational }\end{array}$ & Manuscript & $\begin{array}{l}39 \text { years (range: } \\
14-77 \text { years) }\end{array}$ & Severe TBI \\
\hline Singhal et al. (49) & 36 & $\begin{array}{l}\text { Prospective } \\
\text { observational }\end{array}$ & Manuscript & $\begin{array}{l}34.4 \text { years (range: } \\
17-68 \text { years) }\end{array}$ & Severe TBI \\
\hline
\end{tabular}

Primary: to determine the association between CSF cytokine profiles and patient outcome

Secondary: to determine the association between cytokines and ICP

cylokines and ICP

cytokines and electrophysiologic/functional patient outcome

Secondary: none mentioned

\begin{tabular}{lll}
\hline Whalen et al. (50) $27 \quad \begin{array}{l}\text { Prospective } \\
\text { observational }\end{array}$ & Manuscript Unknown "children" Severe TB
\end{tabular}

Primary: to determine the association between CSF

IL-8 levels and patient outcome

Secondary: to determine the association between CSF IL-8 in TBI patients and non-TBI controls $(n=24)$

\begin{tabular}{|c|c|c|c|c|c|c|}
\hline \multicolumn{7}{|c|}{ Neurophysiologic association } \\
\hline \multirow[t]{2}{*}{ Muller et al. (51) } & \multirow[t]{2}{*}{25} & \multirow[t]{2}{*}{$\begin{array}{l}\text { Prospective } \\
\text { observational }\end{array}$} & \multirow[t]{2}{*}{ Manuscript } & \multirow[t]{2}{*}{$\begin{array}{l}41 \text { years (range: } \\
\text { unknown) }\end{array}$} & \multirow[t]{2}{*}{ Severe TBI } & $\begin{array}{l}\text { Primary: to evaluate the relationship between CSF } \\
\text { IL-6, IL-8, and IL-10 with TCD defined CBF }\end{array}$ \\
\hline & & & & & & Secondary: none mentioned \\
\hline \multirow[t]{2}{*}{ Stein et al. (52) } & \multirow{2}{*}{$\begin{array}{c}14 \text { with } \\
\text { CSF } \\
\text { cytokines }\end{array}$} & \multirow[t]{2}{*}{$\begin{array}{l}\text { Prospective } \\
\text { observational }\end{array}$} & \multirow[t]{2}{*}{ Manuscript } & \multirow[t]{2}{*}{$\begin{array}{l}31.6 \text { years (range: } \\
\text { unknown) }\end{array}$} & \multirow[t]{2}{*}{ Severe TBI } & $\begin{array}{l}\text { Primary: to determine the relationship between CSF } \\
\text { cytokines with ICP and patient outcome }\end{array}$ \\
\hline & & & & & & Secondary: none mentioned \\
\hline \multicolumn{7}{|c|}{ Nil association studies } \\
\hline \multirow[t]{2}{*}{ Amick et al. (53) } & \multirow[t]{2}{*}{24} & \multirow[t]{2}{*}{$\begin{array}{l}\text { Prospective } \\
\text { observational }\end{array}$} & \multirow[t]{2}{*}{ Manuscript } & \multirow[t]{2}{*}{$\begin{array}{l}5.4 \text { years (range: } \\
0.2-16 \text { years) }\end{array}$} & \multirow[t]{2}{*}{$\begin{array}{l}\text { Moderate-severe } \\
\text { TBI }\end{array}$} & $\begin{array}{l}\text { Primary: to determine the association between IL-2, } \\
\text { IL-4, IL-6 and IL-12 with patient outcome }\end{array}$ \\
\hline & & & & & & $\begin{array}{l}\text { Secondary: compare IL levels in CSF to non-TBI } \\
\text { controls }(n=12)\end{array}$ \\
\hline \multirow[t]{2}{*}{ Buttram et al. (54) } & \multirow[t]{2}{*}{36} & \multirow[t]{2}{*}{$\begin{array}{l}\text { Prospective } \\
\text { observational }\end{array}$} & \multirow[t]{2}{*}{ Manuscript } & \multirow[t]{2}{*}{$\begin{array}{l}6.9 \text { years (range: } \\
\text { unknown) }\end{array}$} & \multirow[t]{2}{*}{ Severe TBI } & $\begin{array}{l}\text { Primary: to measure CSF cytokines and determine } \\
\text { the impact of moderate hypothermia on expression. } \\
\text { Also determine the link between CSF cytokines and } \\
\text { outcome }\end{array}$ \\
\hline & & & & & & $\begin{array}{l}\text { Secondary: compared CSF cytokine profile to non-TBI } \\
\text { controls }(n=10)\end{array}$ \\
\hline \multirow[t]{2}{*}{ Csuka et al. (55) } & \multirow[t]{2}{*}{28} & \multirow[t]{2}{*}{$\begin{array}{l}\text { Prospective } \\
\text { observational }\end{array}$} & \multirow[t]{2}{*}{ Manuscript } & \multirow[t]{2}{*}{$\begin{array}{l}36 \text { years (range: } \\
16-67 \text { years) }\end{array}$} & \multirow[t]{2}{*}{ Severe TBI } & $\begin{array}{l}\text { Primary: to determine the association between various } \\
\text { CSF and serum cytokines }\end{array}$ \\
\hline & & & & & & $\begin{array}{l}\text { Secondary: to determine the association between CSF } \\
\text { cytokines with outcome and ICP }\end{array}$ \\
\hline
\end{tabular}

(Continued) 
TABLE 2 | Continued

\begin{tabular}{|c|c|c|c|c|c|c|}
\hline Reference & $\begin{array}{l}\text { Number of } \\
\text { patients }\end{array}$ & Study type & $\begin{array}{l}\text { Article } \\
\text { location }\end{array}$ & $\begin{array}{l}\text { Mean age } \\
\text { (years) }\end{array}$ & $\begin{array}{l}\text { Patient } \\
\text { characteristics }\end{array}$ & Primary and secondary goal of study \\
\hline \multirow[t]{2}{*}{ Diamond et al. (56) } & $\begin{array}{l}59 \text { with } \\
\text { CSF } \\
\text { cytokines }\end{array}$ & $\begin{array}{l}\text { Prospective } \\
\text { observational }\end{array}$ & Manuscript & $\begin{array}{l}\text { Unclear mean age } \\
\text { for CSF cytokine } \\
\text { cohort }\end{array}$ & $\begin{array}{l}\text { Moderate-severe } \\
\text { TBI }\end{array}$ & $\begin{array}{l}\text { Primary: to determine the association between } \\
\text { serum and CSF cytokine levels with the development } \\
\text { of PTE }\end{array}$ \\
\hline & & & & & & $\begin{array}{l}\text { Secondary: to compare serum and CSF levels with } \\
\text { healthy control values. Also assess genetic IL-1b } \\
\text { associations with PTE }\end{array}$ \\
\hline \multirow[t]{2}{*}{ Goodman et al. (57) } & 23 & $\begin{array}{l}\text { Prospective } \\
\text { observational }\end{array}$ & Manuscript & $\begin{array}{l}32.7 \text { years (range: } \\
15-57 \text { years) }\end{array}$ & Severe TBI & $\begin{array}{l}\text { Primary: to compare CSF and jugular venous cytokine } \\
\text { profiles }\end{array}$ \\
\hline & & & & & & $\begin{array}{l}\text { Secondary: to compare cytokine profiles to ICP and } \\
\text { CPP }\end{array}$ \\
\hline \multirow[t]{2}{*}{ Gopcevic et al. (58) } & 20 & $\begin{array}{l}\text { Prospective } \\
\text { observational }\end{array}$ & Manuscript & $\begin{array}{l}53 \text { years (range: } \\
\text { unknown) }\end{array}$ & Severe TBI & $\begin{array}{l}\text { Primary: to determine the association between } \\
\text { jugular serum and CSF IL-8 levels with in-hospital } \\
\text { mortality }\end{array}$ \\
\hline & & & & & & $\begin{array}{l}\text { Secondary: to determine the association between } \\
\text { jugular plasm and CSF IL-8 levels }\end{array}$ \\
\hline \multirow[t]{2}{*}{ Lenzlinger et al. (59) } & 41 & $\begin{array}{l}\text { Prospective } \\
\text { observational }\end{array}$ & Manuscript & $\begin{array}{l}38 \text { years (range: } \\
15-74 \text { years) }\end{array}$ & Severe TBI & $\begin{array}{l}\text { Primary: to determine the association between CSF } \\
\text { and serum cytokines with patient outcome }\end{array}$ \\
\hline & & & & & & $\begin{array}{l}\text { Secondary: to compared serum and CSF cytokine } \\
\text { profiles }\end{array}$ \\
\hline \multirow[t]{2}{*}{ Maier et al. (60) } & 29 & $\begin{array}{l}\text { Prospective } \\
\text { observational }\end{array}$ & Manuscript & $\begin{array}{l}54.8 \text { years (range: } \\
16-85 \text { years) }\end{array}$ & Severe TBI & $\begin{array}{l}\text { Primary: to determine the CSF profile for two soluble } \\
\text { tumor necrosis factor receptors (TNFR's) }\end{array}$ \\
\hline & & & & & & $\begin{array}{l}\text { Secondary: to determine the association between CSF } \\
\text { sTNFR levels and patient outcome }\end{array}$ \\
\hline \multirow[t]{2}{*}{ Maier et al. (61) } & 29 & $\begin{array}{l}\text { Prospective } \\
\text { observational }\end{array}$ & Manuscript & $\begin{array}{l}45.5 \text { years (range: } \\
18-75 \text { years) }\end{array}$ & Severe TBI & $\begin{array}{l}\text { Primary: to evaluate the correlation between CSF and } \\
\text { serum cytokine }\end{array}$ \\
\hline & & & & & & $\begin{array}{l}\text { Secondary: to determine the association between } \\
\text { cytokine profile and patient outcome. Also, compare } \\
\text { to CSF from healthy volunteers }(n=35)\end{array}$ \\
\hline \multirow[t]{2}{*}{$\begin{array}{l}\text { Morganti-Kossmann } \\
\text { et al. (62) }\end{array}$} & 42 & Unclear & $\begin{array}{l}\text { Meeting } \\
\text { abstract }\end{array}$ & Unknown & $\begin{array}{l}\text { Severe TBI with } \\
\text { various primary }\end{array}$ & $\begin{array}{l}\text { Primary: to determine the association between serum } \\
\text { and CSF cytokines with injury patterns }\end{array}$ \\
\hline & & & & & $\begin{array}{l}\text { and secondary } \\
\text { injuries }\end{array}$ & $\begin{array}{l}\text { Secondary: to determine the association between } \\
\text { cytokine profiles and patient outcome }\end{array}$ \\
\hline \multirow[t]{2}{*}{ Newell et al. (63) } & 66 & $\begin{array}{l}\text { Retrospective } \\
\text { case series }\end{array}$ & Manuscript & $\begin{array}{l}6 \text { years (range: } \\
0.1-16 \text { years) }\end{array}$ & Severe TBI & $\begin{array}{l}\text { Primary: to measure inflammatory markers in the CSF } \\
\text { linked to T-cell activation }\end{array}$ \\
\hline & & & & & & $\begin{array}{l}\text { Secondary: to comment on the association between } \\
\text { these markers and patient outcome. Also compare } \\
\text { levels to healthy controls }\end{array}$ \\
\hline \multirow[t]{2}{*}{ Ross et al. (64) } & 50 & $\begin{array}{l}\text { Prospective } \\
\text { observational }\end{array}$ & Manuscript & $\begin{array}{l}21 \text { years (range: } \\
4-70 \text { years) }\end{array}$ & Severe TBI & $\begin{array}{l}\text { Primary: to compare serum and CSF TNF-a in TBI } \\
\text { patients to healthy controls }(n=46)\end{array}$ \\
\hline & & & & & & $\begin{array}{l}\text { Secondary: to compare TNF-a levels to patient } \\
\text { outcome }\end{array}$ \\
\hline \multirow[t]{2}{*}{ Uzan et al. (65) } & 11 & $\begin{array}{l}\text { Prospective } \\
\text { observational }\end{array}$ & Manuscript & $\begin{array}{l}28.5 \text { years (range: } \\
2.5-53 \text { years) }\end{array}$ & Severe TBI & $\begin{array}{l}\text { Primary: to determine the association between NO } \\
\text { metabolic products and IL-8 }\end{array}$ \\
\hline & & & & & & $\begin{array}{l}\text { Secondary: to determine the association between NO } \\
\text { and IL-8 with patient outcome }\end{array}$ \\
\hline
\end{tabular}

TBI, traumatic brain injury; sTBI, severe TBI; RCT, randomized control trial; ICP, intracranial pressure; CPP, cerebral perfusion pressure; CSF, cerebrospinal fluid; CBF, cerebral blood flow; $\mathrm{PbtO}_{2}$, partial pressure of oxygen in brain tissue; TCD, transcranial Doppler; DC, decompressive craniectomy; IL, interleukin; a, alpha; b, beta; ra, receptor antagonist; TNF, tumor necrosis factor; NO, nitrous oxide; TNFR, tumor necrosis factor receptor; NGF, nerve growth factor; BDNF, brain-derived neurotrophic factor; GDNF, glial-derived neurotrophic factor; PTE, post-traumatic epilepsy; PTD, post-traumatic depression; PCA, principle component analysis.

of sample collection varied as well, with the typical collection period of 5-7 days.

Numerous different panels of cytokines were evaluated within the CMD samples, across the studies included within the review. The most commonly studied cytokines included IL-1b, IL-1ra, IL-6, IL-8, and IL-10. Details of CMD technique and catheter locations are listed in Table 3.

\section{CSF Cytokine Review}

Sampling of CSF was conducted through external ventricular drains (EVDs) in almost all patients described within the studies included in the CSF cytokine systematic review (30-65). Sampling and analysis frequency varied significantly from study to study with sampling occurring from every $6 \mathrm{~h}$ to daily. Duration of sampling varied as well, up to 21 days post-injury (35). 
TABLE 3 | CMD cytokine measures and outcomes.

\begin{tabular}{|c|c|c|c|c|c|c|}
\hline Reference & $\begin{array}{l}\text { Catheter location and measured CMD } \\
\text { cytokines }\end{array}$ & $\begin{array}{l}\text { Interventional } \\
\text { therapies } \\
\text { applied during } \\
\text { measurement }\end{array}$ & Primary outcome & $\begin{array}{l}\text { Secondary } \\
\text { outcome }\end{array}$ & $\begin{array}{l}\text { Complications } \\
\text { to CMD }\end{array}$ & Conclusions \\
\hline Cederberg et al. (11) & $\begin{array}{l}\text { Mixed locations } \\
\text { IL-6/L-8 } \\
\text { Unclear sampling interval [3 samples in each } \\
\text { patient over course of intensive care unit (ICU) stay] } \\
\text { Perfusate not specified }\end{array}$ & Not specified & $\begin{array}{l}\text { 6/7 patients survived } \\
\text { IL-6 and IL- } 8 \text { was increased in survivors } \\
\text { Peri-lesional location of CMD catheter yielded } \\
\text { higher IL-6 and IL-8 levels }\end{array}$ & N/A & Not specified & $\begin{array}{l}\text { IL-6/L-8 are increase in } \\
\text { CDM both in "healthy" } \\
\text { and peri-lesional tissue }\end{array}$ \\
\hline Figaji et al. (12) & $\begin{array}{l}\text { Unclear locations } \\
\text { IL-1a, IL-1b, IL1-ra, IL-6, IL-8, and IL-10; VEGF, } \\
\text { and MCP-1 } \\
\text { Unclear sampling interval } \\
\text { Perfusate not specified }\end{array}$ & Not specified & $\begin{array}{l}\text { Variable individual cytokine responses } \\
\text { IL- } 6 \text { and IL- } 8 \text { were the most consistently elevated } \\
\text { across all patients }\end{array}$ & N/A & Not specified & $\begin{array}{l}\text { IL-6/L-8 are consistently } \\
\text { increased in CMD in } \\
\text { pediatric sTBI }\end{array}$ \\
\hline Guilfoyle et al. (13) & $\begin{array}{l}2 \times \text { CMD catheters per patients } \\
\text { ( } 1 \text { healthy tissue, } 1 \text { peri-lesional) } \\
\text { "42 cytokines" IL- } 7 \text { and IL-8 } \\
\text { Unclear sampling interval } \\
\text { Perfusate not specified }\end{array}$ & Not specified & $\begin{array}{l}\mathrm{IL}-7(p<0.05) \text { and IL-8 }(<0.05) \text { were found to be } \\
\text { higher in peri-lesional tissue } \\
\text { IL-1b and interferon gamma }(\text { INF-g) were higher in } \\
\text { peri-lesional tissue within the first } 72 \mathrm{~h} \text { post-injury }\end{array}$ & N/A & Not specified & $\begin{array}{l}\text { IL-7/IL-8 are higher in } \\
\text { peri-lesional tissue } \\
\text { IL-1b and INF-g are } \\
\text { higher in peri-lesional } \\
\text { tissue within the first } 72 \mathrm{~h}\end{array}$ \\
\hline aHelmy et al. (14) & $\begin{array}{l}\text { Area of "diffuse injury" } \\
\text { EGF, Eotaxin, FGF-2, fms-like tyrosine kinase } 3 \\
\text { (FIt3) lig, Frac, G-CSF, GM-CSF, GRO, IFN-a2, IFN-g, } \\
\text { IL-1a, IL-1b, IL-1ra, IL-2, IL-3, IL-4, IL-5, } \\
\text { IL-6, IL-7, IL-8, IL-9, IL-10, IL-12p40, IL-12p70, } \\
\text { IL-13, IL-15, IL-17, inducible protein (IP)-10, } \\
\text { MCP-1, MCP-3, MDC, MIP-1a, MIP-1b, PDGF-AA, } \\
\text { PDGF-AAAB, regulated on activation, normal T cell } \\
\text { expressed and secreted (RANTES), sCD40L, } \\
\text { slL-2R, TGF-a, TNF } \\
\text { q6 h pooled sampling over } 5 \text { days } \\
3.5 \% \text { human ablumin solution perfusate }\end{array}$ & Not specified & $\begin{array}{l}\text { IL-1b and TNF are covariate } \\
\text { IL-1ra and IL-1a are covariate } \\
\text { MIP-1a and MIP-1b were coexpressed } \\
\text { Earlier temporal expression of IL-6, GRO, G-CSF, } \\
\text { IP10 compared to IL-10, MCP-3, IL-17 }\end{array}$ & N/A & Not specified & $\begin{array}{l}\text { PCA of CMD cytokine } \\
\text { profiles yields covariate } \\
\text { relationships between } \\
\text { specific cytokines and } \\
\text { temporal expression } \\
\text { pattern }\end{array}$ \\
\hline aHelmy et al. (15) & $\begin{array}{l}\text { Double side-by-side in six patients } \\
\text { (to analyze perfusate), and single catheter } \\
\text { in six patients - unclear tissue location } \\
\text { EGF, Eotaxin, FGF-2, Flt3 lig, Frac, G-CSF, } \\
\text { GM-CSF, GRO, IFN-a2, IFN-g, IL-1a, IL-1b, IL-1ra, } \\
\text { IL-2, IL-3, IL-4, IL-5, IL-6, IL-7, IL-8, IL-9, IL-10, } \\
\text { IL-12p40, IL-12p70, IL-13, IL-15, IL-17, IP-10, } \\
\text { MCP-1, MCP-3, MDC, MIP-1a, MIP-1b, PDGF-AA, } \\
\text { PDGF-AAAB, RANTES, sCD40L, sIL2R, TGFa, TNF } \\
\text { q6 h pooled sampling over } 5 \text { days } \\
\text { Assessed both crystalloid and 3.5\% human } \\
\text { albumin perfusate }\end{array}$ & $\begin{array}{l}\text { Unclear; two } \\
\text { patients under } \\
\text { went DC for } \\
\text { refractory ICP }\end{array}$ & $\begin{array}{l}\text { 1. Albumin perfusate led to significantly higher } \\
\text { fluid recovery compared to crystalloid. Albumin } \\
\text { perfusate led to significantly higher cytokine } \\
\text { recovery (18 cyotkines) } \\
\text { 2. Brain concentrations of } 23 \text { cytokines were } \\
\text { significantly higher than jugular plasma } \\
\text { concentrations (ex. IL-1ra, IL-1a, IL-1b, IL-6, } \\
\text { IL-8, IL-10, IL-12p70, MCP-1) } \\
\text { Many cytokines displayed a temporal expression, } \\
\text { with expression within the first } 72 \text { h (e.g., TNF, } \\
\text { IL-7, IL-8, MIP1a, sCD40L, IL-1 } 13, \text { GRO, PDGF, AA, } \\
\text { RANTES, MIP-1b, IL-1ra, G-CSF, IP10, IL-6) }\end{array}$ & N/A & Not specified & $\begin{array}{l}\text { 1. Ablumin CMD } \\
\text { perfusate led to } \\
\text { increased fluid and } \\
\text { cytokine recovery } \\
\text { 2. Brain cytokine } \\
\text { concentrations were } \\
\text { significantly higher } \\
\text { than jugular plasma } \\
\text { for } 23 \text { cytokines. } \\
\text { Many cytokines } \\
\text { displayed a temporal } \\
\text { expression patter with } \\
\text { early expression } \\
\text { post-injury }(72 \mathrm{~h})\end{array}$ \\
\hline
\end{tabular}


TABLE 3 | Continued

\begin{tabular}{|c|c|c|c|c|c|c|}
\hline Reference & $\begin{array}{l}\text { Catheter location and measured CMD } \\
\text { cytokines }\end{array}$ & $\begin{array}{l}\text { Interventional } \\
\text { therapies } \\
\text { applied during } \\
\text { measurement }\end{array}$ & Primary outcome & $\begin{array}{l}\text { Secondary } \\
\text { outcome }\end{array}$ & $\begin{array}{l}\text { Complications } \\
\text { to CMD }\end{array}$ & Conclusions \\
\hline bHelmy et al. (16) & $\begin{array}{l}\text { Right frontal location (in setting of diffuse injury) } \\
42 \text { cytokine array } \\
\mathrm{q} 6 \mathrm{~h} \text { pooled sampling for } 5 \text { days } \\
\text { Isotonic central nervous system perfusate }\end{array}$ & $\begin{array}{l}\text { Group } 1(n=10) \text { : } \\
\text { after baseline } 6 \mathrm{~h} \\
\text { CMD samples; } \\
\text { received } 100 \mathrm{mg} \\
\text { rhlL-1ra subcut } \\
\text { Repeated q24 } \mathrm{h} \\
\text { for total of five } \\
\text { doses } \\
\text { Group } 2(n=10) \text { : } \\
\text { control group } \\
\text { No specifics } \\
\text { on other ICU } \\
\text { therapies }\end{array}$ & $\begin{array}{l}\text { 1. No complications secondary to rhlL-1ra were } \\
\text { seen. } \\
\text { 2. CMD IL-1ra concentrations were significantly } \\
\text { higher in the treatment group vs. control } \\
(p=0.02) \text {, with variation over time }(p<0.0001) \\
\text { 3. MDC was significantly lower in the rhIL-1ra } \\
(p=0.05)\end{array}$ & $\mathrm{N} / \mathrm{A}$ & Not specified & $\begin{array}{l}\text { 1. rhlL-1ra appears safe } \\
\text { in severe diffuse TBI } \\
\text { 2. rhlL-1ra reaches the } \\
\text { brain extracellular fluid } \\
\text { 3. MDC was lower in the } \\
\text { rhlL-1 } 1 \text { ra group }\end{array}$ \\
\hline bHelmy et al. (17) & $\begin{array}{l}\text { Right frontal location (in setting of diffuse injury) } \\
42 \text { cytokine array } \\
96 \mathrm{~h} \text { pooled sampling for } 5 \text { days } \\
3.5 \% \text { human albumin perfusate }\end{array}$ & $\begin{array}{l}\text { Group } 1(n=10) \text { : } \\
\text { after baseline } 6 \mathrm{~h} \\
\text { CMD samples; } \\
\text { received } 100 \mathrm{mg} \\
\text { rhlL-1ra subcut } \\
\text { Repeated q24 } \mathrm{h} \\
\text { for total of five } \\
\text { doses } \\
\text { Group } 2(n=10) \text { : } \\
\text { control group } \\
\text { No specifics } \\
\text { on other ICU } \\
\text { therapies }\end{array}$ & $\begin{array}{l}\text { Based on PCA it was found that cytokines } \\
\text { associated with macrophage recruitment were } \\
\text { decreased in the rhIL-1ra group (MIP-1a, MCP-3, } \\
\text { Fractalkine, GM-CSF) }\end{array}$ & $\mathrm{N} / \mathrm{A}$ & Not specified & $\begin{array}{l}\text { CMD macrophage base } \\
\text { cytokines are decreased } \\
\text { in rhlL-1ra-treated } \\
\text { patients }\end{array}$ \\
\hline Hillman et al. (18) & $\begin{array}{l}\text { Paired CMD catheter placement in peri-lesional } \\
\text { tissue } \\
\text { IL-6 } \\
\text { q6 } \mathrm{h} \text { pooled analysis } \\
\text { Ringer's/dextran } 60 \text { or human albumin perfusate }\end{array}$ & Not specified & $\begin{array}{l}\text { CMD IL-6 concentrations varied depending on } \\
\text { underlying condition and secondary injury (i.e., } \\
\text { ischemia) } \\
\text { The temporal expression of CMD measured IL-6 } \\
\text { varied between patients }\end{array}$ & $\mathrm{N} / \mathrm{A}$ & $\begin{array}{l}1 \text { catheter } \\
\text { membrane failure }\end{array}$ & $\begin{array}{l}\text { CMD IL-6 concentrations } \\
\text { varied from patient to } \\
\text { patient and depending } \\
\text { on initial and secondary } \\
\text { injury patterns }\end{array}$ \\
\hline Hillman et al. (19) & $\begin{array}{l}\text { Peri-lesional tissue } \\
\text { IL-1b, IL-6 } \\
\text { q6 h pooled analysis } \\
3.5 \% \text { human albumin perfusate }\end{array}$ & Not specified & $\begin{array}{l}\mathrm{CMD} \text { biochemical evidence of ischemia (LPR }>30 \\
\text { and glutamate }>80 \mu \mathrm{mol} / \mathrm{L} \text { for } 24 \mathrm{~h} \text { period) was } \\
\text { associated with significant IL- } 6 \text { increase }(p<0.01) \text {, } \\
\text { which subsided after } ~ 90 \mathrm{~h} \text { post-injury }(p<0.001) \\
\text { In those patients without biochemical ischemia, IL-6 } \\
\text { levels spiked in the first } 48 \mathrm{~h}(p<0.01 \text { ) } \\
\text { IL-1b activation was less commonly observed (only } \\
53 \% \text { of measures) }\end{array}$ & $N / A$ & Not specified & $\begin{array}{l}\text { CMD IL-6 displays a } \\
\text { correlation with CMD } \\
\text { biochemical ischemia } \\
\text { and a temporal } \\
\text { correlation post-injury } \\
\text { (in the absence of } \\
\text { biochemical ischemia) }\end{array}$ \\
\hline
\end{tabular}




\begin{tabular}{|c|c|c|c|c|c|c|}
\hline Reference & $\begin{array}{l}\text { Catheter location and measured CMD } \\
\text { cytokines }\end{array}$ & $\begin{array}{l}\text { Interventional } \\
\text { therapies } \\
\text { applied during } \\
\text { measurement }\end{array}$ & Primary outcome & $\begin{array}{l}\text { Secondary } \\
\text { outcome }\end{array}$ & $\begin{array}{l}\text { Complications } \\
\text { to CMD }\end{array}$ & Conclusions \\
\hline Hutchinson et al. (20) & $\begin{array}{l}\text { Unclear tissue location ("frontal cortex") } \\
\text { IL-1a, IL-1b, IL-1ra } \\
\text { q6 h pooled samples (mean no. samples = 9.1; } \\
\text { range = 4-23) } \\
\text { Isotonic central nervous system perfusate }\end{array}$ & Not specified & $\begin{array}{l}\text { IL-1a and IL-1b concentrations were lower than } \\
\text { IL-1ra } \\
\text { A positive correlation between IL-1ra and IL-1b was } \\
\text { seen ( } P=0.028) \\
\text { No correlation between IL- } 1 \mathrm{~b} \text { and IL-1ra was found } \\
\text { No correlation between cytokines and CMD glucose, } \\
\text { glutamate, LPR }\end{array}$ & $\begin{array}{l}\text { ICP: ICP was } \\
\text { negatively } \\
\text { correlation } \\
\text { to IL-1ra } \\
\text { ( }=0.041 \text { ) } \\
\text { No correlation } \\
\text { between other } \\
\text { cytokines and } \\
\text { ICP } \\
\text { No correlation } \\
\text { between } \\
\text { cytokines and } \\
\text { CPP } \\
\text { Outcome: } \\
\text { significant } \\
\text { relationship } \\
\text { between } \\
\text { mean IL-1ra } \\
\text { levels and } \\
\text { poor outcome } \\
\text { (dichotomized } \\
\text { GOS at } \\
6 \text { months) } \\
\text { ( } p=0.018) \text { - } \\
\text { high } \\
\text { IL-1ra was } \\
\text { associated } \\
\text { with good } \\
\text { outcome } \\
\text { No relationship } \\
\text { between IL-1a } \\
\text { and IL-1b with } \\
\text { outcome }\end{array}$ & Not specified & $\begin{array}{l}\text { 1. The appears to be a } \\
\text { correlation between } \\
\text { IL-1ra and IL-1b } \\
\text { 2. There is a negative } \\
\text { correlation between } \\
\text { ICP and IL-1ra } \\
\text { 3. Mean IL-1ra levels } \\
\text { correlate to patient } \\
\text { outcome at } 6 \text { months }\end{array}$ \\
\hline Mellergard et al. (21) & $\begin{array}{l}\text { Mixed locations; some patients with two catheters } \\
\text { (unclear which patients) } \\
\text { IL-1b, IL-6, IL-8, FGF-2, MIP-1b, RANTES, VEGF, } \\
\text { IL-10 } \\
\text { q6 h pooled samples for } 36 \mathrm{~h} \\
\text { Ringer-dextran } 60 \text { perfusate }\end{array}$ & Not specified & $\begin{array}{l}\text { IL-1b peaked in the first } 12 \mathrm{~h} \text { period } \\
\text { IL-6 peaked after } 12 \mathrm{~h} \text { post-insertion } \\
\text { IL-8 peaked within the first } 6 \mathrm{~h} \text { post-insertion } \\
\text { MIP-1b peaked within the first } 6 \mathrm{~h} \text { post-insertion } \\
\text { FGF-2 peaked within the first } 6 \mathrm{~h} \text { post-insertion } \\
\text { IL-10, VEGF, and RANTES did not show a temporal } \\
\text { profile }\end{array}$ & N/A & Not specified & $\begin{array}{l}\text { CMD catheter insertion } \\
\text { leads to IL-1b/L-6/ } \\
\text { IL-8/MIP1b within the } \\
\text { first } 6-12 \mathrm{~h} \text {, which } \\
\text { then decrease during } \\
\text { the subsequent time } \\
\text { afterward }\end{array}$ \\
\hline
\end{tabular}


TABLE 3 | Continued

\begin{tabular}{|c|c|c|c|c|c|c|}
\hline Reference & $\begin{array}{l}\text { Catheter location and measured CMD } \\
\text { cytokines }\end{array}$ & $\begin{array}{l}\text { Interventional } \\
\text { therapies } \\
\text { applied during } \\
\text { measurement }\end{array}$ & Primary outcome & $\begin{array}{l}\text { Secondary } \\
\text { outcome }\end{array}$ & $\begin{array}{l}\text { Complications } \\
\text { to CMD }\end{array}$ & Conclusions \\
\hline cMellergard et al. (22) & $\begin{array}{l}\text { Paired catheters ( } 1 \text { peri-lesonal; } 1 \text { healthy tissue)- } \\
\text { used the catheter with highest glycerol levels for } \\
\text { measuring cytokines } \\
\text { IL-1b, IL-6, IL-10 } \\
\text { q6 h pooled analysis for } 7 \text { days } \\
\text { Ringer-dextran } 60 \text { perfusate }\end{array}$ & $\begin{array}{l}\text { Not specified; } \\
\text { various surgical } \\
\text { procedure for } \\
\text { hemotomas in } \\
\text { TBI group }\end{array}$ & $\begin{array}{l}\text { IL- } 1 \mathrm{~b} \text { increased during the first } 48 \mathrm{~h} \text {, and then } \\
\text { decreased } \\
\text { IL- } 6 \text { increased over the first } 48 \mathrm{~h} \text {, and then } \\
\text { decreased } \\
\text { IL-10 remained elevated throughout the } \\
\text { measurement period }\end{array}$ & N/A & Not specified & $\begin{array}{l}\text { IL- } 1 \mathrm{~b} \text { and IL- } 6 \text { display a } \\
\text { peak elevation during the } \\
\text { first } 48 \mathrm{~h} \text { post-TBI } \\
\text { IL-10 remains elevated } \\
\text { through the first } 7 \text { days } \\
\text { post-TBI }\end{array}$ \\
\hline 'Mellergard et al. (23) & $\begin{array}{l}\text { Paired catheters ( } 1 \text { peri-lesonal; } 1 \text { healthy tissue)- } \\
\text { used the catheter with highest glycerol levels for } \\
\text { measuring cytokines } \\
\text { FGF-2, VEGF } \\
\text { q6 h pooled analysis for } 7 \text { days } \\
\text { Ringer-dextran } 60 \text { perfusate }\end{array}$ & $\begin{array}{l}\text { Not specified; } \\
\text { various surgical } \\
\text { procedure for } \\
\text { hemotomas in } \\
\text { TBI group }\end{array}$ & $\begin{array}{l}\text { FGF-2 levels peaked at day } 3 \text { post-TBI } \\
\text { VEGF levels peaked on day } 2 \text { post-TBI }\end{array}$ & N/A & Not specified & $\begin{array}{l}\text { FGF-2NEGF levels } \\
\text { peaked on days } 3 \text { and } 2 \\
\text { post-TBl }\end{array}$ \\
\hline Mellergard et al. (24) & $\begin{array}{l}\text { Unclear location } \\
\text { IL-1b, IL-6, IL-8, FGF-2, MIP-1b, RANTES, VEGF, } \\
\text { IL-10 } \\
\text { q6 h pooled sample analysis } \\
\text { Ringer-dextran } 60 \text { perfusate }\end{array}$ & $\begin{array}{l}\text { Local protocols; } \\
\text { not otherwise } \\
\text { specified }\end{array}$ & $\begin{array}{l}\text { IL-1b, IL-8, and IL-10 did not display age-related } \\
\text { differences } \\
\text { VEGF, MIP-1b, and RANTES were different in the } \\
<25 \text { years age group vs. over } 25 \text { years age } \\
\text { FGF-2 levels were significantly higher in the } \\
>65 \text {-year-old group }(p<0.0001)\end{array}$ & N/A & Not specified & $\begin{array}{l}\text { There may be an age- } \\
\text { related difference in the } \\
\text { expression of VEGF, } \\
\text { MIP-1b, RANTES, and } \\
\text { FGF-2 post-TBI }\end{array}$ \\
\hline Mondello et al. (25) & $\begin{array}{l}\text { Unclear location } \\
\text { IL-1b, IL-6, TNF-a, INF-g } \\
\text { Unclear sampling interval } \\
\text { Unclear perfusate }\end{array}$ & Not specified & $\begin{array}{l}\text { IL-6 showed high initial values that then decreased, } \\
\text { in contrast IL-1beta, TNF-alpha and INF-gamma } \\
\text { showed later elevations } \\
\text { UCH-L1 levels negatively correlated }(p<0.05) \text { with } \\
\text { IL-1beta, widely used biomarker of inflammation }\end{array}$ & N/A & Not specified & $\begin{array}{l}\text { Variable cytokine } \\
\text { temporal profiles are } \\
\text { seen post-TB| }\end{array}$ \\
\hline $\begin{array}{l}\text { Parez-Barcena } \\
\text { et al. (26) }\end{array}$ & $\begin{array}{l}\text { Right frontal location; unclear tissue quality } \\
\text { IL-1b, IL-6, IL-8, IL } 10, \text { IL-12, TNF-a } \\
\text { q8 h sample analysis (up to } 248 \mathrm{~h} \text { duration) } \\
\text { Isotonic central nervous system perfusate }\end{array}$ & $\begin{array}{l}\text { Varied ICP/ } \\
\text { CPP directed } \\
\text { therapies; } \\
\text { some use of } \\
\text { barbiturates }\end{array}$ & $\begin{array}{l}\text { IL-1b, IL-6, and IL-8 peaked during first } 24 \mathrm{~h} \\
\text { post-injury } \\
\text { IL-10 remained unchanged during the sampling } \\
\text { period }\end{array}$ & $\begin{array}{l}\text { ICP: no } \\
\text { correlation } \\
\text { between } \\
\mathrm{IL}-1 \mathrm{~b}, \mathrm{IL}-6 \text {, } \\
\mathrm{IL}-8 \text { and IL-10 } \\
\text { with ICP } \\
\mathrm{PbtO}_{2} \text { : } \\
\text { no clear } \\
\text { correlation } \\
\text { between } \\
\text { cytokines and } \\
\mathrm{PbtO}_{2}\end{array}$ & Not specified & $\begin{array}{l}\text { 1. IL-1b, IL-6 and IL-8 } \\
\text { peaked within the first } \\
24 \mathrm{~h} \text { post-injury } \\
\text { 2. No clear association } \\
\text { was found between } \\
\text { cytokines and ICP, } \\
\mathrm{PbtO}_{2} \text {, CT changes }\end{array}$ \\
\hline
\end{tabular}




measurement

\begin{tabular}{|c|c|c|c|c|c|c|}
\hline & & & & $\begin{array}{l}\text { CT: no } \\
\text { association } \\
\text { found } \\
\text { between } \\
\text { cytokines and } \\
\text { subsequent } \\
\text { CT defined } \\
\text { swelling or } \\
\text { lesion change }\end{array}$ & & \\
\hline Roberts et al. (27) & $\begin{array}{l}\text { Healthy tissue } \\
\text { IL-1a, IL-1b, IL-2, IL-4, IL-5, IL-6, IL-8, IL-10, and } \\
\text { TNF-a } \\
\text { q6 h pooled analysis (up to } 156 \mathrm{~h} \text { of monitoring) } \\
\text { Isotonic central nervous system perfusate }\end{array}$ & $\begin{array}{l}\text { Varied; one } \\
\text { patient had DC }\end{array}$ & $\begin{array}{l}\text { IL-1a, IL-1b, and TNF-a were elevated initially after } \\
\text { injury } \\
\text { IL-6 and IL- } 8 \text { were substantially higher in the CMD } \\
\text { compared to other cytokines } \\
\text { IL-5 was barely detectable } \\
\text { Similar cytokine concentrations were seen in CSF } \\
\text { and CMD, which were both substantially higher than } \\
\text { jugular plasma sampled } \\
\text { Increase CMD concentrations of MMP- } 8 \text { and MMP- } \\
9 \text { were seen with increases in the levels of IL-1a, } \\
\text { IL-2, and IL-1a and -2 and TNF-a, respectively. In } \\
\text { contrast, the CMD levels of MMP-7 decreased with } \\
\text { increases in IL-1b, IL-2, and IL-6 }\end{array}$ & $\begin{array}{l}\text { Neuro Exam: } \\
\text { IL-1b, IL-4 } \\
\text { and TNF-a } \\
\text { levels were } \\
\text { substantially } \\
\text { higher in those } \\
\text { with loss } \\
\text { of pupillary } \\
\text { reactivity } \\
\text { ICP: IL-2 } \\
\text { displayed } \\
\text { a negative } \\
\text { correlation to } \\
\text { ICP } \\
\text { TNF-a } \\
\text { displayed } \\
\text { a negative } \\
\text { correlation to } \\
\text { ICP } \\
\text { CPP: IL-6 and } \\
\text { IL-8 displayed } \\
\text { a negative } \\
\text { correlation to } \\
\text { CPP } \\
\text { PbtO } \\
\text { c: no } \\
\text { correlation } \\
\text { found } \\
\text { between } \\
\text { cytokines and } \\
\text { PbtO }_{2} \\
\text { Outcome: no } \\
\text { correlation } \\
\text { between } \\
\text { cytokines and } \\
\text { GOS }\end{array}$ & Not specified & $\begin{array}{l}\text { 1. IL-1a, IL-1b, TNF-a, } \\
\text { IL-6 and IL-8 } \\
\text { predominate the } \\
\text { cytokine response } \\
\text { post TBI } \\
\text { 2. Various patterns of } \\
\text { MMP changes are } \\
\text { seen in correlation } \\
\text { with changes in } \\
\text { cytokine expression } \\
\text { 3. IL-1b, IL-4 and TNF-a } \\
\text { levels were higher } \\
\text { in those with loss of } \\
\text { pupillary reactivity } \\
\text { 4. IL-6 and IL-8 } \\
\text { correlation with CPP. } \\
\text { TNF-a correlations } \\
\text { with ICP }\end{array}$ \\
\hline
\end{tabular}


TABLE 3 | Continued

\begin{tabular}{|c|c|c|c|c|c|c|}
\hline Reference & $\begin{array}{l}\text { Catheter location and measured CMD } \\
\text { cytokines }\end{array}$ & $\begin{array}{l}\text { Interventional } \\
\text { therapies } \\
\text { applied during } \\
\text { measurement }\end{array}$ & Primary outcome & $\begin{array}{l}\text { Secondary } \\
\text { outcome }\end{array}$ & $\begin{array}{l}\text { Complications } \\
\text { to CMD }\end{array}$ & Conclusions \\
\hline Winter et al. (28) & $\begin{array}{l}\text { Peri-lesional } \\
\text { IL-1b, IL-6, NGF } \\
\text { q3 h sampling (for } 6 \text { days) } \\
\text { Normal saline perfusate }\end{array}$ & Not specified & CMD cytokine analysis is feasible and safe & $\begin{array}{l}\text { Peak cytokine } \\
\text { levels were } \\
\text { seen within } \\
\text { the first } 36 \mathrm{~h} \\
\text { post-injury } \\
\text { IL-1b } \\
\text { predominated } \\
\text { with } \\
\text { substantially } \\
\text { higher } \\
\text { concentrations } \\
\text { compared to } \\
\text { IL-6 and NGF } \\
\text { IL-6 was high } \\
\text { in survivors, } \\
\text { while NGF } \\
\text { was lower in } \\
\text { non-survivors }\end{array}$ & None & $\begin{array}{l}\text { 1. CMD cytokine } \\
\text { analysis is feasible } \\
\text { 2. IL-1b may be the } \\
\text { predominant } C M D \\
\text { cytokine expressed } \\
\text { 3. Unclear patterns } \\
\text { in survivors vs. } \\
\text { non-survivors }\end{array}$ \\
\hline Winter et al. (29) & $\begin{array}{l}\text { Healthy tissue } \\
\text { IL-1b, IL-6, NGF } \\
\text { q3 h sampling } \\
\text { Normal saline perfusate }\end{array}$ & Not specified & $\begin{array}{l}\text { Higher IL-6 was seen in survivors }(p=0.04) \\
\text { Peak IL-6 correlated to GOS at } 6 \text { months }(p=0.03) \\
\text { Peak NGF:IL-1b ratios were significantly lower in } \\
\text { survivors ( } p=0.01 \text { ) }\end{array}$ & N/A & None & $\begin{array}{l}\text { IL-6 levels in CMD } \\
\text { samples may correlation } \\
\text { to survival and GOS at } \\
6 \text { months }\end{array}$ \\
\hline
\end{tabular}

TBI, traumatic brain injury; STBI, severe TBl; GOS, Glasgow outcome scale; CMD, cerebral microdialysis; RCT, randomized control trial; ICP, intracranial pressure; CT, computed tomography; PbtO ${ }_{2}$, brain tissue oxygen monitoring; CPP, cerebral perfusion pressure; CSF, cerebrospinal fluid; LPR, lactate:pyruvate ratio; DC, decompressive craniectomy; $\mu$ mol, micromolar; $m m$ Hg, millimeters of mercury; L, liter; $\mu$ mol, micromolar; IL, interleukin; a, alpha; b, beta; 9 , gamma; TNF, tumor necrosis factor; INF, interferon; MCP, monocyte chemoattractant protein; MIPS, macrophage inflammatory proteins; TGF, transforming growth factor; NGF, nerve growth factor; BDNF, brain-derived neurotrophic factor; GDNF, glial-derived neurotrophic factor; TNFR, tumor necrosis factor receptor; GM-CSF, granulocyte macrophage colony stimulating factor; sVCAM, soluble vascular cell adhesion molecule; sICAM, soluble intracellular adhesion molecule; PDGF, platelet-derived growth factor; VEGF, vascular endothelial growth factor; MDC, macrophage-derived chemokine; FGFR, fibroblast growth factor receptor.

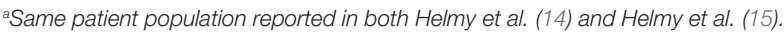

${ }^{b}$ Same patient population described in Helmy et al. (16) and Helmy et al. (17).

"Same patient population reported in both Mellergard et al. (22) and Mellergard et al. (23). 
TABLE 4 | CSF cytokine measures and outcomes.

\begin{tabular}{|c|c|c|c|c|c|c|}
\hline Reference & $\begin{array}{l}\text { Interval of cytokine } \\
\text { measure }\end{array}$ & $\begin{array}{l}\text { Measured CMD } \\
\text { cytokines }\end{array}$ & $\begin{array}{l}\text { Interventional therapies } \\
\text { applied during measurement }\end{array}$ & $\begin{array}{l}\text { Outcome(s) of interest (patient outcome, } \\
\text { neurophysiologic outcome, tissue outcome) }\end{array}$ & Other outcomes & Conclusions \\
\hline Abboud et al. (30) & $\begin{array}{l}\text { q12-h Intervals for } \\
5 \text { days }\end{array}$ & $\begin{array}{l}\text { IL-1 } \alpha, \text { IL-1 } \beta, \text { IL-2, IL-4, } \\
\text { IL-5, IL-6, IL-8, IL-10, } \\
\text { IL-13, MIP-1a, MIP- } \\
\text { 1b, TNF-a, VEGF }\end{array}$ & Not specified & $\begin{array}{l}\text { GOS at } 6 \text { and } 12 \text { months post-injury } \\
\text { Statistically significant differences in IL-4, IL-5, IL-6, } \\
\text { IL-8, IL-13, and TNF- } \alpha \text { (all } p<0.05 \text { ) were observed } \\
\text { between TBI survivors vs. non-survivors over } 5 \text { days }\end{array}$ & $\mathrm{N} / \mathrm{A}$ & $\begin{array}{l}\text { Elevated IL-4, IL-6, IL-8, IL-23, } \\
\text { and TNF-a levels may be } \\
\text { associated with poor outcome } \\
\text { at } 6 \text { and } 12 \text { months } \\
\text { Similarly, low IL-5 and IL-13 } \\
\text { may be associated with poor } \\
\text { outcome }\end{array}$ \\
\hline Bell et al. (31) & $\begin{array}{l}\text { q24-h Intervals for } \\
3 \text { days } \\
\text { Control group had } \\
\text { banked CSF }\end{array}$ & IL-6, IL-10 & $\begin{array}{l}\text { High variable; barbiturates } \\
\text { and various ICP/CPP-directed } \\
\text { therapies }\end{array}$ & $\begin{array}{l}\text { Mortality (at unclear interval) } \\
\text { IL- } 6 \text { is not associated with mortality } \\
\text { IL-10 is associated with mortality }(p=0.022)\end{array}$ & $\begin{array}{l}\mathrm{IL}-6 \text { and } \mathrm{IL}-10 \text { levels } \\
\text { were increased } \\
\text { compared to controls }\end{array}$ & $\begin{array}{l}\text { Elevated IL-10 levels may be } \\
\text { associated with mortality }\end{array}$ \\
\hline Chiaretti et al. (32) & $\begin{array}{l}\text { At } 2 \text { and } 48 \mathrm{~h} \\
\text { post-injury } \\
\text { Controls were initially } \\
\text { investigated for } \\
\text { meningitis but were } \\
\text { found to be negative. } \\
\text { CSF was banked }\end{array}$ & IL-6, NGF & $\begin{array}{l}\text { Highly protocolized therapy; } \\
\text { seemingly homogenous between } \\
\text { patients }\end{array}$ & $\begin{array}{l}\text { GOS at } 6 \text { months } \\
\text { Low IL- } 6 \text { and NGF at } 2 \text { h post-injury was associated } \\
\text { with good outcome }(p<0.01) \\
\text { Increased IL- } 6 \text { variation between the two time points } \\
\text { was correlated with better outcome }\end{array}$ & $\begin{array}{l}\text { IL-6 and NGF were } \\
\text { both elevated and } \\
\text { increased between } \\
\text { the two sampling } \\
\text { periods } \\
\text { IL-6 and NGF were } \\
\text { positively correlated } \\
\text { at both time periods }\end{array}$ & $\begin{array}{l}\text { Lower IL- } 6 \text { and NGF levels } \\
\text { early post-TBI may be } \\
\text { associated with better } \\
\text { outcome at } 6 \text { months }\end{array}$ \\
\hline Chiaretti et al. (33) & $\begin{array}{l}\text { At } 2 \text { and } 48 \mathrm{~h} \\
\text { post-injury }\end{array}$ & $\begin{array}{l}\text { IL-1b, IL-6, NGF, } \\
\text { BDNF, GDNF }\end{array}$ & $\begin{array}{l}\text { Highly protocolized therapy; } \\
\text { seemingly homogenous between } \\
\text { patients }\end{array}$ & $\begin{array}{l}\text { GOS at } 6 \text { months } \\
\text { Low NGF at } 2 \mathrm{~h}(p<0.01) \text { and high NGF/IL-6 } \\
(p=0.02 / p<0.01) \text { at } 48 \mathrm{~h} \text { were associated with } \\
\text { better outcome } \\
\text { Low IL-1b at } 48 \mathrm{~h} \text { was associated with better } \\
\text { outcome }(p<0.01)\end{array}$ & $\mathrm{N} / \mathrm{A}$ & $\begin{array}{l}\text { Low initial NGF, followed by } \\
\text { increased NGF/L- } 6 \text { may be } \\
\text { associated with good outcome } \\
\text { at } 6 \text { months } \\
\text { Low IL-1b at } 48 \text { h may } \\
\text { be associated with better } \\
\text { outcome at } 6 \text { months }\end{array}$ \\
\hline Chiaretti et al. (34) & $\begin{array}{l}\text { At } 2 \text { and } 24 \mathrm{~h} \\
\text { post-injury }\end{array}$ & IL-1b and IL-6 & $\begin{array}{l}\text { Highly protocolized therapy; } \\
\text { seemingly homogenous between } \\
\text { patients }\end{array}$ & $\begin{array}{l}\text { Dichotomized GOS at } 6 \text { months (good }=4 \text { or } 5 \text {; } \\
\text { poor }=3 \text { or less) } \\
\text { Higher CSF IL-1b and IL- } 6 \text { at both } 2 \mathrm{~h} \text { and } 24 \mathrm{~h} \\
\text { were seen in those patients with poor outcome at } \\
6 \text { months }\end{array}$ & $\begin{array}{l}\mathrm{IL}-1 \mathrm{~b} \text { and IL-6 at } 2 \mathrm{~h} \\
\text { were higher in the TBI } \\
\text { cohort }\end{array}$ & $\begin{array}{l}\text { Elevated IL-1b and IL- } 6 \text { at } \\
\text { both } 2 \text { and } 24 \mathrm{~h} \text { post-injury } \\
\text { may be associate with poor } \\
\text { outcome at } 6 \text { months }\end{array}$ \\
\hline Hans et al. (35) & $\begin{array}{l}\text { Daily CSF samples up } \\
\text { to } 21 \text { days post-injury }\end{array}$ & IL-6 and sIL-6R & Not specified & $\begin{array}{l}\text { Dichotomized GOS at } 6 \text { months (good }=4 \text { or } 5 \text {; } \\
\text { poor }=3 \text { or less) } \\
\text { High IL6/sIL-6R was associated with poor outcome } \\
\text { at } 6 \text { months }\end{array}$ & $\begin{array}{l}\text { CSF levels of IL-6 and } \\
\text { slL-6R were higher } \\
\text { than compared to } \\
\text { plasma }\end{array}$ & $\begin{array}{l}\text { Elevated IL-6/sIL-6R may be } \\
\text { associated with poor outcome } \\
\text { at } 6 \text { months }\end{array}$ \\
\hline Hayakata et al. (36) & $\begin{array}{l}6,12,24,48,72, \text { and } \\
96 \mathrm{~h} \text { after injury }\end{array}$ & $\begin{array}{l}\text { TNF-a, IL-1, IL-6, IL-8, } \\
\text { and IL-10 }\end{array}$ & $\begin{array}{l}\text { Varied therapies; hypothermia } \\
\text { and other ICP/CPP-directed } \\
\text { approaches }\end{array}$ & $\begin{array}{l}\text { Dichotomized GOS at } 6 \text { months (good }=4 \text { or } 5 \text {; } \\
\text { poor }=3 \text { or less) } \\
\text { CSF IL- } 1 \text { b was found to be higher in those with poor } \\
\text { outcome }\end{array}$ & $\begin{array}{l}\text { ICP: IL- } 1 \mathrm{~b} \text { was } \\
\text { significantly positively } \\
\text { correlated with ICP } \\
\text { throughout the entire } \\
\text { study }(p<0.05)\end{array}$ & $\begin{array}{l}\text { 1. Elevated IL-1b may be } \\
\text { associated with poor } \\
\text { outcome at } 6 \text { months } \\
\text { 2. Elevated IL-1b may be } \\
\text { associated with elevated ICP }\end{array}$ \\
\hline
\end{tabular}




\begin{tabular}{|c|c|c|c|c|c|c|}
\hline Reference & $\begin{array}{l}\text { Interval of cytokine } \\
\text { measure }\end{array}$ & $\begin{array}{l}\text { Measured CMD } \\
\text { cytokines }\end{array}$ & $\begin{array}{l}\text { Interventional therapies } \\
\text { applied during measurement }\end{array}$ & $\begin{array}{l}\text { Outcome(s) of interest (patient outcome, } \\
\text { neurophysiologic outcome, tissue outcome) }\end{array}$ & Other outcomes & Conclusions \\
\hline & & & & & $\begin{array}{l}\text { Various cytokine } \\
\text { elevations were } \\
\text { seen during S100B } \\
\text { elevations. IL-1b } \\
\text { peaks was correlated } \\
\text { with } \mathrm{S} 100 \mathrm{~B} \text { peak } \\
(p<0.005)\end{array}$ & \\
\hline Jamil et al. (37) & $\begin{array}{l}\text { Unclear interval; } \\
\text { "acute" period } \\
\text { post-TBI }\end{array}$ & $\begin{array}{l}\text { IL-1b, IL-4, IL-5, } \\
\text { IL-6, IL-7, IL-8, } \\
\text { IL-10, IL-12, TNF-a, } \\
\text { sICAM-1, sVCAM-1, } \\
\text { SFAS }\end{array}$ & Not specified & $\begin{array}{l}\text { Patient health questionnaire (PHQ-9) at } 6 \text { and } \\
12 \text { months post-injury } \\
\text { Acute CSF IL- } 6(p=0.008), \text { IL-8 }(p=0.034) \text {, } \\
\text { and ICAM1 }(p=0.025 \text { ) levels were higher among } \\
\text { patients who would go on to develop depression } \\
6 \text { months after injury } \\
\text { Acute CSF TNF-a ( } p=0.036), I L-4(p=0.007) \text {, and } \\
\text { IL-1b }(p=0.001) \text { levels were individually associated } \\
\text { with lower depression risk at } 12 \text { months post-injury }\end{array}$ & $\mathrm{N} / \mathrm{A}$ & $\begin{array}{l}\text { 1. Elevated IL-6 and IL-8 } \\
\text { may be associate with } \\
\text { depression at } 6 \\
\text { 2. TNF-a, IL-4, and IL-1b may } \\
\text { be associated with lower } \\
\text { chance of depression at } \\
12 \text { months }\end{array}$ \\
\hline Juengst et al. (38) & $\begin{array}{l}\text { Within first week of } \\
\text { injury }\end{array}$ & $\begin{array}{l}\text { IL-4, IL-5, IL-8, IL-12, } \\
\text { TNF-a, sVCAM, } \\
\text { sICAM }\end{array}$ & Not specified & $\begin{array}{l}\text { Apathy subscale of the frontal systems behavior } \\
\text { scale, collected at } 6 \text { and } 12 \text { months post-TBI } \\
\text { Higher acute CSF IL5, sVCAM, and SICAM with } \\
\text { apathy at } 6 \text { months and lower acute serum } \\
\text { TNFalpha, IL8, and IL5 with apathy at } 12 \text { months } \\
(p<0.05)\end{array}$ & $N / A$ & $\begin{array}{l}\text { Higher acute CSF IL5, SVCAM, } \\
\text { and sICAM with apathy at } \\
6 \text { months and lower acute } \\
\text { serum TNFalpha, IL8, and IL5 } \\
\text { with apathy at } 12 \text { months }\end{array}$ \\
\hline Juengst et al. (39) & $\begin{array}{l}2 \text { times daily for } \\
6 \text { days }\end{array}$ & TNF-a & Not specified & $\begin{array}{l}\text { At } 6 \text { and } 12 \text { months post-injury, FrSBe disinhibition } \\
\text { subscale; suicidal endorsement was assessed by } \\
\text { the PHQ-9 } \\
\text { No relationship between TNF-a in CSF and } \\
\text { suicidality at } 6 \text { or } 12 \text { months } \\
\text { Acute serum TNFa levels were inversely associated } \\
\text { with } 12 \text {-month disinhibition ( } r=0.520, p=0.027 \text { ) } \\
\text { and achieved borderline significance with } 6 \text {-month } \\
\text { disinhibition ( } r=0.470, p=0.057 \text { ) }\end{array}$ & $\begin{array}{l}\text { TBI patients had } \\
\text { significantly higher } \\
\text { CSF TNF-a levels } \\
\text { compared to controls }\end{array}$ & $\begin{array}{l}\text { Acute levels of TNF-a may } \\
\text { correlate to } 6 \text { and } 12 \text { month } \\
\text { rates of disinhibition }\end{array}$ \\
\hline Juengst et al. (40) & $\begin{array}{l}2 \text { times daily up to } \\
6 \text { days }\end{array}$ & $\begin{array}{l}\text { IL-1 } \beta, \text { IL-4, IL-5, } \\
\text { IL-6, IL-7, IL-8, } \\
\text { IL-10, IL-12, TNF-a, } \\
\text { sVCAM-1, sICAM-1, } \\
\text { sFAS }\end{array}$ & Not specified & $\begin{array}{l}\text { PHQ- } 9 \text { was administered to participants at } 6 \text { and } \\
12 \text { months after injury } \\
\text { The inflammatory cell surface markers sVCAM-1, } \\
\text { sICAM- } 1 \text {, and sFAS in the CSF were each positively } \\
\text { associated with PTD at } 6 \text { months ( } p<0.02 \text { for all } \\
\text { comparisons). } \\
\text { The cytokine IL-8 was positively associated with } \\
\text { PTD at } 12 \text { months ( } p<0.02) \text {, while the cytokine IL-7 } \\
\text { was inversely associated with PTD at } 12 \text { months } \\
(p<0.05)\end{array}$ & $\begin{array}{l}\text { IL-1 } \beta, \text { IL-4, IL-6, IL-7, } \\
\text { IL-8, IL-10, TNF- } \alpha \text {, } \\
\text { sVCAM-1, sICAM-1, } \\
\text { and sFAS ( } p<0.05 \text { ) } \\
\text { were significantly } \\
\text { elevated compared } \\
\text { to controls }\end{array}$ & $\begin{array}{l}\text { 1. Elevated SVCAM-1, } \\
\text { sICAM-1 and SFAS may } \\
\text { be associated with PTD at } \\
6 \text { months } \\
\text { 2. Elevated IL-7 and IL-8 may } \\
\text { be associated with PTD at } \\
12 \text { months }\end{array}$ \\
\hline Kirchhoff et al. (41) & $\begin{array}{l}\text { Upon EVD insertion, } \\
\text { then at } 12,24 \text {, and } \\
48 \mathrm{~h} \text { post-injury }\end{array}$ & $\mathbb{I L}-10$ & Not specified & $\begin{array}{l}\text { Mortality at unspecified interval } \\
\text { IL-10 was significantly higher in non-survivors }\end{array}$ & $\begin{array}{l}\text { IL-10 was higher at all } \\
\text { time points compared } \\
\text { to non-TBI controls }\end{array}$ & $\begin{array}{l}\text { Elevated CSF IL-10 at } \\
\text { admission was associated } \\
\text { with mortality }\end{array}$ \\
\hline
\end{tabular}




\begin{tabular}{|c|c|c|c|c|c|c|}
\hline Reference & $\begin{array}{l}\text { Interval of cytokine } \\
\text { measure }\end{array}$ & $\begin{array}{l}\text { Measured CMD } \\
\text { cytokines }\end{array}$ & $\begin{array}{l}\text { Interventional therapies } \\
\text { applied during measurement }\end{array}$ & $\begin{array}{l}\text { Outcome(s) of interest (patient outcome, } \\
\text { neurophysiologic outcome, tissue outcome) }\end{array}$ & Other outcomes & Conclusions \\
\hline & $\begin{array}{l}\text { Control group: CSF } \\
\text { gained from spinal } \\
\text { anesthetics in elective } \\
\text { non-TBI surgical } \\
\text { cases }\end{array}$ & & & & & \\
\hline $\begin{array}{l}\text { Kossmann } \\
\text { et al. (42) }\end{array}$ & $\begin{array}{l}\text { q24 h for unclear } \\
\text { duration } \\
\text { Control group: non- } \\
\text { TBI patients (1 VPS } \\
\text { and } 2 \text { Dx LP) }\end{array}$ & $\begin{array}{l}\text { IL1b, IL-6, TNF-a, } \\
\text { NGF }\end{array}$ & $\begin{array}{l}\text { Various therapies; heterogeneous } \\
\text { across population }\end{array}$ & $\begin{array}{l}\text { Dichotomized GOS at } 3 \text { months (good }=4 \text { or } 5 \text {; } \\
\text { poor }=3 \text { or less) } \\
\text { High IL-6 levels were associated with NGF presence } \\
\text { in CSF } \\
\text { NGF levels were elevated in those with better } \\
\text { outcomes }\end{array}$ & $\begin{array}{l}\text { IL-6 and NGF were } \\
\text { high in TBI patients } \\
\text { compared to control } \\
\text { samples }\end{array}$ & $\begin{array}{l}\text { NGF may be elevated in those } \\
\text { with good outcome }\end{array}$ \\
\hline Kumar et al. (43) & $\begin{array}{l}2 \text { times daily for } \\
5 \text { days }\end{array}$ & IL-6 & Not specified & $\begin{array}{l}\text { Dichotomized GOS at } 6 \text { and } 12 \text { months (good }=4 \\
\text { or } 5 \text {; poor }=3 \text { or less) } \\
\text { Association between high IL-6 upon admission and } \\
6 \text {-month GOS ( } p=0.003 \text { ) }\end{array}$ & $\begin{array}{l}\text { IL-6 levels were } \\
\text { higher in TBI } \\
\text { compared to controls }\end{array}$ & $\begin{array}{l}\text { High IL-6 during the first } \\
5 \text { days of injury may be } \\
\text { associated with poor outcome } \\
\text { at } 6 \text { months }\end{array}$ \\
\hline Kumar et al. (44) & $\begin{array}{l}2 \text { times daily for up to } \\
5 \text { days }\end{array}$ & $\begin{array}{l}\text { IL-1 } \beta, \text { IL-4, IL-5, } \\
\text { IL-6, IL-7, IL-8, } \\
\text { IL-10, IL-12, TNF-a, } \\
\text { sVCAM-1, sICAM-1, } \\
\text { sFAS }\end{array}$ & Not specified & $\begin{array}{l}\text { Trichotomized GOS at } 6 \text { and } 12 \text { months (good }=4 \\
\text { or } 5 \text {; poor }=3 \text { or } 2 \text {; dead }=1 \text { ) } \\
\text { Individuals in cluster } 1 \text { (increased sICAM- } 1 \text {, sFAS, } \\
\text { IL-10, IL-6, sVCAM-1, IL-5, and IL-8) had a } 10.9 \\
\text { times increased likelihood of GOS scores of } 2 / 3 \text { vs. } \\
4 / 5 \text { at } 6 \text { months compared to cluster } 2 \text { (increased } \\
\text { IL-12, IL7, IL-4) }\end{array}$ & $\begin{array}{l}\text { Cytokines were } \\
\text { elevated in TBI } \\
\text { patients compared to } \\
\text { controls }\end{array}$ & $\begin{array}{l}\text { Elevated IL-5, IL-6, IL-8, IL-10, } \\
\text { sVCAM-1, and sICMA-1 } \\
\text { may be associated with poor } \\
\text { outcome at } 6 \text { months }\end{array}$ \\
\hline Kushi et al. (45) & $\begin{array}{l}\text { Admission, } 24,72 \text {, } \\
\text { and } 168 \mathrm{~h} \text { post-injury }\end{array}$ & IL-6, IL-8 & $\begin{array}{l}\text { High protocolized treatment; fairly } \\
\text { homogeneous therapy }\end{array}$ & $\begin{array}{l}\text { Mortality at unspecified interval } \\
\text { IL-6 and IL-8 levels were significantly higher in CSF } \\
\text { compared to serum } \\
\text { IL-6 and IL-8 levels were significantly higher in } \\
\text { non-survivors }\end{array}$ & N/A & $\begin{array}{l}\text { Elevated IL- } 6 \text { and IL- } 8 \text { during } \\
\text { the first week post-TBI may be } \\
\text { associated with mortality }\end{array}$ \\
\hline $\begin{array}{l}\text { Nwachuku } \\
\text { et al. (46) }\end{array}$ & q6 $\mathrm{h}$ for 5 days & $\begin{array}{l}\text { IL-1b, IL-6, TNF-a, } \\
\text { IFN-a, IL-12p70, } \\
\text { IL-10, and IL-8 }\end{array}$ & Not specified & $\begin{array}{l}\text { Dichotomized GOS at } 3,6,12 \text {, and } 24 \text { months } \\
\text { (good = } 4 \text { or 5; poor }=3 \text { or less) } \\
\text { Mean } 5 \text {-day levels of IFN-a, IL-10, IL-12 p70, IL-1, } \\
\text { IL-6, IL-8, and TNF-a were associated with outcome } \\
(p<0.05)\end{array}$ & N/A & $\begin{array}{l}\text { Elevated mean } 5 \text {-day levels } \\
\text { of various cytokines may be } \\
\text { associated with poor outcome } \\
\text { at } 3,6,12 \text {, and } 24 \text { months } \\
\text { post-injury }\end{array}$ \\
\hline $\begin{array}{l}\text { Santarseiri } \\
\text { et al. (47) }\end{array}$ & $\begin{array}{l}2 \text { times daily for up to } \\
6 \text { days }\end{array}$ & $\begin{array}{l}\text { IL-1 } \beta, \text { IL-4, IL-5, } \\
\text { IL-6, IL-7, IL-8, } \\
\text { IL-10, IL-12, TNF-a, } \\
\text { sVCAM-1, sICAM-1, } \\
\text { sFAS }\end{array}$ & Not specified & $\begin{array}{l}\text { Dichotomized GOS at } 6 \text { months (good }=4 \text { or } 5 \text {; } \\
\text { poor }=3 \text { or less) } \\
\text { Cortisol: high cortisol patients were more likely to } \\
\text { have elevated IL-10, IL-1b, IL-6, sFas, sICAM- } 1 \text {, } \\
\text { sVCAM-1 and TNFa }(p<0.01 \text { all comparisons, } \\
\text { except IL-1b, } p<0.05 \text { ) compared to low cortisol } \\
\text { patients } \\
\text { Outcome: significant associations between GOS } \\
\text { and mean levels of IL-10, IL-6, IL-8, sFas, sICAM-1 } \\
(p<0.01 \text { ) and TNF-a }(p<0.05 \text { ), with lower levels } \\
\text { associated with favorable outcome }\end{array}$ & $\mathrm{N} / \mathrm{A}$ & $\begin{array}{l}\text { Low mean IL-6, IL-8, IL-10, } \\
\text { sICAM-1, and TNF-a may be } \\
\text { associated with good outcome } \\
\text { at } 6 \text { months post-injury }\end{array}$ \\
\hline
\end{tabular}




\begin{tabular}{|c|c|c|c|c|c|c|}
\hline Reference & $\begin{array}{l}\text { Interval of cytokine } \\
\text { measure }\end{array}$ & $\begin{array}{l}\text { Measured CMD } \\
\text { cytokines }\end{array}$ & $\begin{array}{l}\text { Interventional therapies } \\
\text { applied during measurement }\end{array}$ & $\begin{array}{l}\text { Outcome(s) of interest (patient outcome, } \\
\text { neurophysiologic outcome, tissue outcome) }\end{array}$ & Other outcomes & Conclusions \\
\hline Shiozaki et al. (48) & $\begin{array}{l}\mathrm{q} 6 \mathrm{~h} \text { for unclear } \\
\text { duration }\end{array}$ & $\begin{array}{l}\text { IL-1b, IL-1ra, IL10, } \\
\text { TNF-a, sTNFr-I }\end{array}$ & Highly Protocolized therapy & $\begin{array}{l}\text { Dichotomized GOS at } 6 \text { months (good }=4 \text { or } 5 \text {; } \\
\text { poor }=3 \text { or less) } \\
\text { IL- } 1 \text { b, IL-1ra, sTNFr-I, and IL- } 10 \text { were significantly } \\
\text { higher in patients with an unfavorable outcome than } \\
\text { in patients with a favorable outcome }(p=0.006 \text {, } \\
p=0.009, p=0.003 \text {, and } p=0.012 \text {, respectively) }\end{array}$ & $\begin{array}{l}\text { IL-1b, IL-1ra, sTNFr-I, } \\
\text { and IL-10 were } \\
\text { significantly higher } \\
\text { in patients with high } \\
\text { ICP than those with } \\
\text { low ICP } p=0.002 \text {, } \\
p=0.006, p=0.009 \text {, } \\
\text { and } p=0.009 \text {, } \\
\text { respectively). } \\
\text { However, the CSF } \\
\text { concentrations of } \\
\text { TNF-a did not differ } \\
\text { between patients with } \\
\text { high ICP and those } \\
\text { with low ICP }\end{array}$ & $\begin{array}{l}\text { 1. Elevated IL-Ib, IL-1ra, } \\
\text { IL-10, and sTNFr-I may } \\
\text { be associated with poor } \\
\text { outcome at } 6 \text { months } \\
\text { 2. Elevated IL-1b, IL-1ra, } \\
\text { IL-10, sTNFr-I may be } \\
\text { associated with high ICP }\end{array}$ \\
\hline Singhal et al. (49) & Unclear interval & $\| \mathrm{L}-1 \mathrm{~b}, \mathrm{IL}-6$ & Not specified & $\begin{array}{l}\text { SSEP: positive correlation between IL-6 and SSEP96 } \\
\text { (mean change in SSEP over } 96 \text { h) }(p=0.0133) \\
\text { Outcome: GOS at } 3 \text { months } \\
\text { Peak IL-6 levels were associated with good outcome } \\
(p=0.026 \text { ) }\end{array}$ & $\mathrm{N} / \mathrm{A}$ & $\begin{array}{l}\text { 1. Elevated IL-6 may be } \\
\text { positively correlated to } \\
\text { SSEP over the first } 96 \mathrm{~h} \\
\text { 2. Peak IL-6 levels may be } \\
\text { associated with outcome at } \\
3 \text { months }\end{array}$ \\
\hline Whalen et al. (50) & $\begin{array}{l}\text { Unclear sampling } \\
\text { intervals }\end{array}$ & IL-8 & Not specified & $\begin{array}{l}\text { Mortality at unspecified interval } \\
\text { Elevated CSF IL-8 levels were associated with } \\
\text { mortality }(p=0.01)\end{array}$ & $\begin{array}{l}\text { IL-8 levels were } \\
\text { elevated compared to } \\
\text { controls }\end{array}$ & $\begin{array}{l}\text { Elevated IL-8 levels during } \\
\text { the first week of injury may be } \\
\text { associated with mortality }\end{array}$ \\
\hline \multicolumn{7}{|c|}{ Neurophysiologic association } \\
\hline Muller et al. (51) & Daily for 7 days & IL-6, IL-8, IL-10 & Not specified & $\begin{array}{l}\text { Transcranial doppler (TCD)-defined cerebral blood } \\
\text { flow velocity } \\
\text { Mean IL- } 6 \text { and IL-8 level were significantly correlated } \\
\text { to MCBFV ( } r=-0.341 \text { and }-0.361 \text {, respectively; } \\
p<0.05 \text { ) }\end{array}$ & $\mathrm{N} / \mathrm{A}$ & $\begin{array}{l}\text { Elevated IL- } 6 \text { and IL- } 8 \text { in the } \\
\text { first } 7 \text { days may be negatively } \\
\text { correlated to TCD defined } \\
\text { MCBFV }\end{array}$ \\
\hline Stein et al. (52) & $\begin{array}{l}2 \text { times daily for } \\
7 \text { days }\end{array}$ & $\begin{array}{l}\text { IL-1b, IL-6, IL-8, } \\
\text { IL-10, and TNF-a }\end{array}$ & High protocolized therapy & $\begin{array}{l}\text { ICP: negative association between early (within first } \\
12 \mathrm{~h} \text { of injury) IL- } 6 \text { and ICP }(p=0.004 \text { ) } \\
\text { Positive correlation between time spent with CPP } \\
\text { below } 60 \mathrm{~mm} \mathrm{Hg} \text { and IL- } 8 \text { levels }(p=0.001 \text { ) } \\
\text { Outcome: dichotomized GOSE at } 6 \text { months } \\
\text { (good }=5-8 \text {; poor }=1-4 \text { ) } \\
\text { No association between CSF cytokines and outcome }\end{array}$ & $N / A$ & $\begin{array}{l}\text { 1. Elevated IL-6 within the } \\
\text { first } 12 \mathrm{~h} \text { of injury may be } \\
\text { associated with low ICP } \\
\text { 2. Elevated IL-8 levels may be } \\
\text { associated with low CPP }\end{array}$ \\
\hline
\end{tabular}

\section{Nil association studies}

\begin{tabular}{|c|c|c|c|c|c|c|}
\hline Amick et al. (53) & $\begin{array}{l}\text { Unclear time frame } \\
\text { post-TBI (from } 4 \text { to } \\
122 \text { h after injury) }\end{array}$ & IL-2, IL-4, IL-6, IL-12 & $\begin{array}{l}\text { Highly variable; barbiturates } \\
\text { and various ICP/CPP-directed } \\
\text { therapies }\end{array}$ & GOS at 6 months post-Injury & $\begin{array}{l}\text { IL- } 6 \text { and IL-12 were } \\
\text { increased compared } \\
\text { to control group }\end{array}$ & $\begin{array}{l}\text { No association between IL-2, } \\
\text { IL-4, IL-6, and IL-12 with GOS } \\
\text { at } 6 \text { months }\end{array}$ \\
\hline
\end{tabular}




\begin{tabular}{|c|c|c|c|c|c|c|}
\hline Reference & $\begin{array}{l}\text { Interval of cytokine } \\
\text { measure }\end{array}$ & $\begin{array}{l}\text { Measured CMD } \\
\text { cytokines }\end{array}$ & $\begin{array}{l}\text { Interventional therapies } \\
\text { applied during measurement }\end{array}$ & $\begin{array}{l}\text { Outcome(s) of interest (patient outcome, } \\
\text { neurophysiologic outcome, tissue outcome) }\end{array}$ & Other outcomes & Conclusions \\
\hline & $\begin{array}{l}\text { Banked samples from } \\
\text { a non-TBI control } \\
\text { group }(n=12) ; \\
\text { CSF gained from } \\
\text { investigations for } \\
\text { meningitis }\end{array}$ & & & $\begin{array}{l}\text { No correlation between measured CSF cytokines } \\
\text { and GOS }\end{array}$ & & \\
\hline Buttram et al. (54) & $\begin{array}{l}\text { Collected } 18,24,48 \text {, } \\
\text { and } 72 \mathrm{~h} \text { post-injury }\end{array}$ & $\begin{array}{l}\text { IL-1a, IL-1b, IL-2, } \\
\text { IL-4, IL-5, IL-6, IL-7, } \\
\text { IL-8, IL-10, IL-12p70, } \\
\text { IL-13, IL-15, IL-17, } \\
\text { IP-10, eotaxin, TNF-a, } \\
\text { INF-g, MCP-1, MIP-1a }\end{array}$ & $\begin{array}{l}\text { Not well specified; half the groups } \\
\text { was subjected to moderate } \\
\text { hypothermia for } 48 \mathrm{~h}\left(32-33^{\circ} \mathrm{C}\right)\end{array}$ & $\begin{array}{l}\text { Dichotomized GOS at } 6 \text { months } \\
\text { No association between CSF cytokines and outcome }\end{array}$ & $\begin{array}{l}\text { Cytokine levels in } \\
\text { TBI patients were } \\
\text { significantly higher } \\
\text { compared to controls }\end{array}$ & $\begin{array}{l}\text { There is no association } \\
\text { between CSF cytokines and } \\
\text { outcome at } 6 \text { months }\end{array}$ \\
\hline Csuka et al. (55) & $\begin{array}{l}\text { Daily until EVD } \\
\text { removal }\end{array}$ & $\begin{array}{l}\text { IL-6, IL-10, TNF-a, } \\
\text { TGF-B1 }\end{array}$ & $\begin{array}{l}\text { Unclear ICP/CPP-directed } \\
\text { therapies }\end{array}$ & $\begin{array}{l}\text { Outcome: GOS at 3-6 months } \\
\text { No correlation found between cytokines and }\end{array}$ & $\begin{array}{l}\mathrm{IL}-10 \text { was found } \\
\text { in both CSF and }\end{array}$ & $\begin{array}{l}\text { CSF cytokines do not correlate } \\
\text { to outcome at 3-6 months }\end{array}$ \\
\hline & & & & $\begin{array}{l}\text { outcome } \\
\text { ICP: no correlation between cytokines and ICP }\end{array}$ & $\begin{array}{l}\text { serum during the } \\
\text { measurement period }\end{array}$ & $\begin{array}{l}\text { CSF cytokines do not correlate } \\
\text { to ICP }\end{array}$ \\
\hline Diamond et al. (56) & $\mathrm{q} 12 \mathrm{~h}$ for 6 days & IL1b & Not specified & $\begin{array}{l}\text { EEG and Epileptologist defined PTE } \\
\text { CSF IL-1b was not statistically associated with PTE }\end{array}$ & $\begin{array}{l}\text { Serum IL-1b levels } \\
\text { was associated with } \\
\text { PTE }\end{array}$ & $\begin{array}{l}\text { CSF IL-1b levels within the } \\
\text { first week of injury is not } \\
\text { associated with PTE }\end{array}$ \\
\hline Goodman et al. (57) & $\begin{array}{l}\text { Unclear sampling } \\
\text { interval }\end{array}$ & $\begin{array}{l}\text { IL-1, IL-6, IL-8, IL-10, } \\
\text { IL-12, TNF }\end{array}$ & Not specified & $\begin{array}{l}\text { ICP/CPP: no correlation between CSF cytokines and } \\
\text { ICP or CPP }\end{array}$ & $\begin{array}{l}\text { Serum and CSF IL-6 } \\
\text { and IL-8 were both } \\
\text { elevated consistently }\end{array}$ & $\begin{array}{l}\text { CSF cytokines are not } \\
\text { associated with changes in } \\
\text { ICP and CPP }\end{array}$ \\
\hline Gopcevic et al. (58) & $\begin{array}{l}\text { Unclear sampling } \\
\text { interval }\end{array}$ & IL-8 & Not specified & $\begin{array}{l}\text { 30-day in-hospital mortality: no correlation between } \\
\text { CSF IL-8 levels and patient outcome }\end{array}$ & $\begin{array}{l}\text { No correlation } \\
\text { between plasma and } \\
\text { CSF IL-8 levels }\end{array}$ & $\begin{array}{l}\text { CSF IL-8 is not associated } \\
\text { with in-hospital mortality at } \\
1 \text { month }\end{array}$ \\
\hline \multirow[t]{2}{*}{ Lenzlinger et al. (59) } & \multirow[t]{2}{*}{$\begin{array}{l}\text { Daily for unclear } \\
\text { duration }\end{array}$} & \multirow[t]{2}{*}{$\begin{array}{l}\text { slL-2R, B2M, } \\
\text { neopterin }\end{array}$} & \multirow[t]{2}{*}{ Unclear ICP direct therapy } & GOS at 4-6 months & $\begin{array}{l}\text { Neopterin levels were } \\
\text { higher in CSF than } \\
\text { serum }\end{array}$ & \multirow[t]{2}{*}{$\begin{array}{l}\text { sIL-2R, B2M, and neopterin } \\
\text { in CSF have no correlation to } \\
\text { outcome at } 4-6 \text { months }\end{array}$} \\
\hline & & & & $\begin{array}{l}\text { No association between measured cytokines and } \\
\text { outcome }\end{array}$ & $\begin{array}{l}\text { B2M and sIL-2R levels } \\
\text { were higher in serum }\end{array}$ & \\
\hline Maier et al. (60) & $\begin{array}{l}\text { Admission and daily } \\
\text { up to day } 10\end{array}$ & $\begin{array}{l}\text { sTNFRp55, } \\
\text { sTNFRp75 }\end{array}$ & Not specified & $\begin{array}{l}\text { GOS at } 6 \text { months } \\
\text { No correlation between sTNFRp55 or sTNFRp } 75 \\
\text { and outcome }\end{array}$ & $\begin{array}{l}\text { sTNRFp55 and } \\
\text { STNFRp75 is } \\
\text { elevated in CSF } \\
\text { compared to control }\end{array}$ & $\begin{array}{l}\text { STNFRp } 55 \text { and sTNFRp } 75 \\
\text { CSF levels are not associated } \\
\text { with outcome at } 6 \text { months }\end{array}$ \\
\hline Maier et al. (61) & $\begin{array}{l}\text { Admission and daily } \\
\text { up to day } 14\end{array}$ & IL-6, IL-8, IL-10 & Not specified & $\begin{array}{l}\text { Mortality at unspecified interval } \\
\text { No correlation between CSF cytokines and patient } \\
\text { outcome }\end{array}$ & $\begin{array}{l}\text { IL-6 and IL-8 were } \\
\text { directly correlated with } \\
\text { each other with CSF } \\
\text { level higher than serum } \\
\text { All measured } \\
\text { cytokines were } \\
\text { higher in TBI patients } \\
\text { compared to controls }\end{array}$ & $\begin{array}{l}\text { CSF IL-6, IL-8, and IL-10 } \\
\text { levels do not correlated with } \\
\text { mortality }\end{array}$ \\
\hline
\end{tabular}




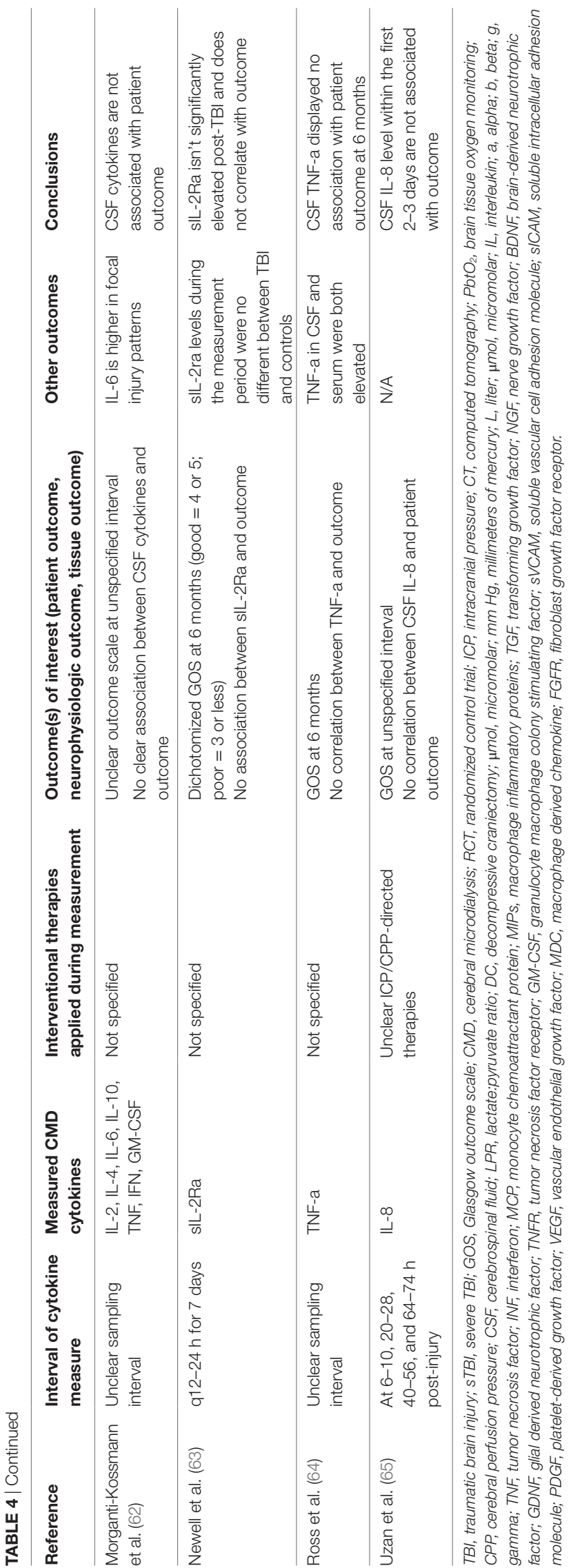

Like the CMD cytokine papers, the CSF cytokine papers included in this review reported the measurement of various cytokines. The most commonly measured cytokines in CSF reported were IL-1b, IL-1ra, IL-6, IL-8, IL-10, and TNF. The details of CSF sampling and specific cytokines measured can be found in Table 4.

\section{Outcomes CMD Cytokine Review}

Given that the CMD cytokine portion of this review was a scoping review of all the literature on CMD cytokines in sTBI, the goals and outcomes reported by the studies were heterogenous, and are listed in Table 3.

Only one study described an intervention during the assessment of CMD cytokines. This study was a prospective RCT describing the application of subcutaneous rhIL-1 ra post severe diffuse TBI (16). The results described both elevated CMD IL-1ra levels and a reduction in MDC in the IL-1ra treated group. The follow-up retrospective statistical analysis of all CMD measured cytokines described a trend toward an increase in M1-microglia related cytokine activation following administration of rhIL-1ra (17).

Three studies reported the correlation between CMD cytokines and patient outcome $(11,20,29)$. Two studies reported a positive association between elevated CMD IL- 6 and improved survival, with one describing improved Glasgow Outcome Scale (GOS) at 6 months $(p=0.03)$. One study reported the negative correlation between CMD IL-1ra and poor GOS at 6 months $(p=0.018)$.

Most studies reported the CMD cytokine profile post-TBI and temporal fluctuations $(12,14,15,21,24,26,27)$. Given the myriad of cytokines measured across the studies, it is impossible to describe all of the relationships. Highlighted details can be found in Table 3. The main findings included elevated IL-1b, IL-6, and IL-8 within the first $48-72 \mathrm{~h}$ post-injury, with these cytokines also displaying peaks during these times (21-23). The CMD IL-10 levels were found to be more uniformly elevated during the sampling periods $(22,26)$. Finally, some coexpression relationships were found between IL-1b with TNF, IL-1ra with IL-1a, and MIP-1a with MIP-1b (14).

Two studies evaluated the CMD cytokine profile associated with secondary events while in the ICU $(18,19)$. CMD IL-6 levels were positively associated with episodes of ischemia/metabolic stress, as defined by a lactate:pyruvate ratio greater than 30 and glutamate levels greater than $80 \mu \mathrm{mol} / \mathrm{L}$.

The relationship of catheter location to CMD cytokine levels was discussed in a couple of papers, with peri-lesional tissue displaying higher cytokine expressions than distant or healthy tissue locations $(11,13)$. Evaluation of catheter technology (18) and cytokine measure feasibility (28) were also described in a few studies.

\section{CSF Cytokine Review}

The 36 papers included in the CSF systematic review (30-65) included both manuscripts, which reported positive associations between CSF cytokine levels and neurophysiologic or patient outcome (30-52), and studies reporting no association (53-65) 


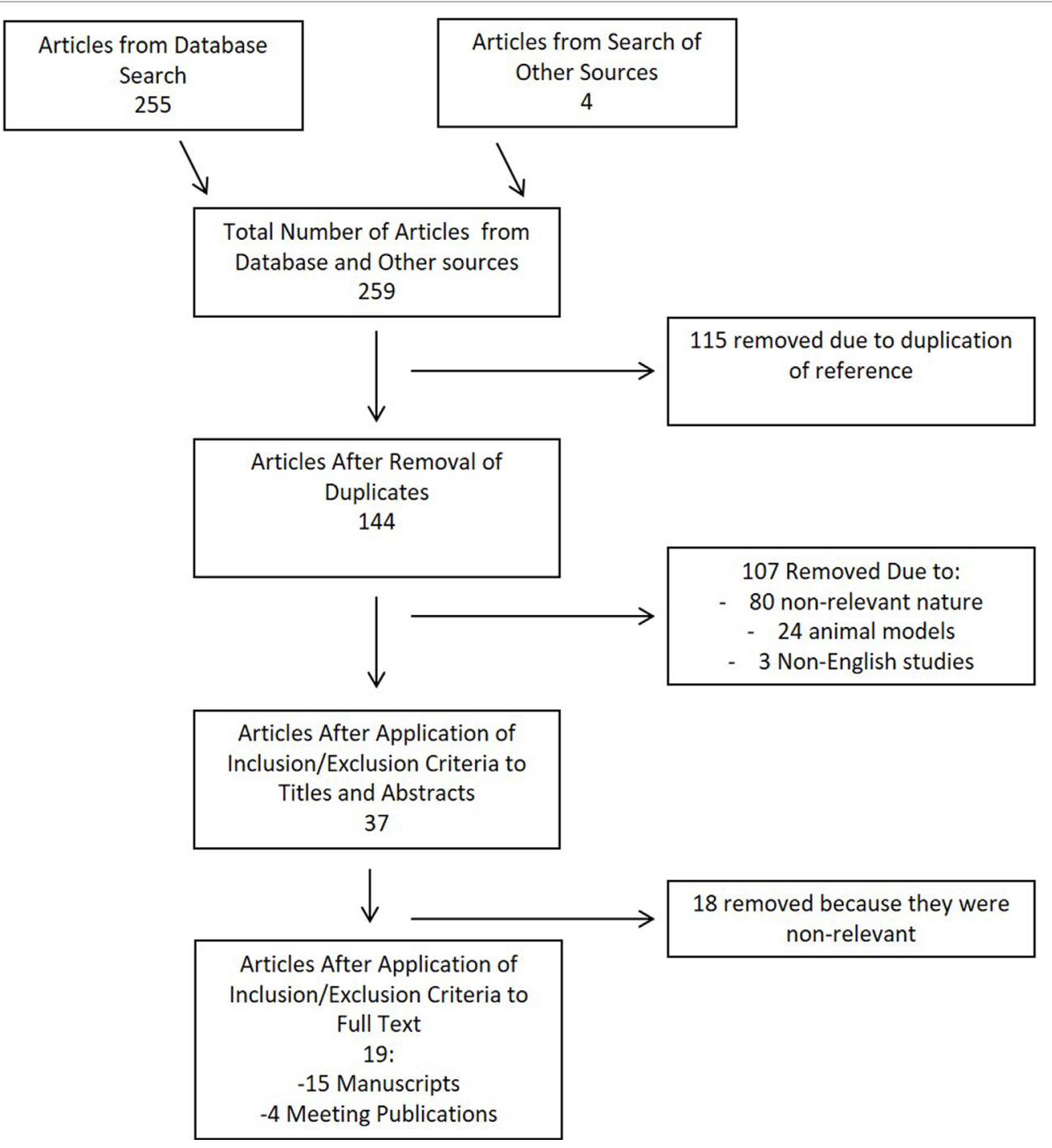

FIGURE 1 | Flow diagram of search results for cerebral microdialysis review.

(i.e., "nil association") between CSF cytokines and the outcomes of interest for the CSF cytokine systematic review. No studies reported an association, "nil" or otherwise, between CSF cytokine measures and tissue outcome as assessed by follow-up neuroimaging. The subsections below describe more details of these outcomes of interest, with further information found in Table 4.

\section{Positive Association Studies}

Twenty-three papers included within the CSF cytokine review found associations between cytokine levels and both neurophysiologic and patient outcomes. Twenty-one described the association between CSF cytokines and patient outcome (30-50). Five papers discussed the association between CSF cytokine measures and neurophysiologic outcomes $(36,48,49,51,52)$.

Patient Outcome. Cerebrospinal fluid levels of several cytokines were related to functional patient outcomes. The most common outcomes specified were: overall mortality or GOS at
6-12 months post-injury. The strongest relationships between cytokines and patient outcome were for IL-1b, IL-1ra, IL-6, IL-8, IL-10, and TNF.

A strong positive correlation between CSF measured IL-6 and IL- 8 with poor GOS was the most commonly described relation between CSF cytokines and patient outcome (30, 32, 35, 36, $42-47,49,50)$. Similarly, a strong association between elevated CSF measured IL-10 and poor patient outcome was described in five studies $(31,41,46-48)$. Elevated CSF IL-1b was found to be associated with mortality and worse GOS at 6 months in four studies $(33,34,36,49)$. Finally, CSF TNF-alpha (TNF-a) levels were found to be associated with worse patient outcome in two studies $(30,46)$.

The relationship between CSF cytokine levels and neuropsychiatric outcome was described in four studies (37-40). These associations included: higher IL- 6 and IL- 8 were associated with a higher incidence of depression at 6 months (37), TNF-a levels with depression at 12 months (37), IL-5/IL-8/IL-12/TBF with 


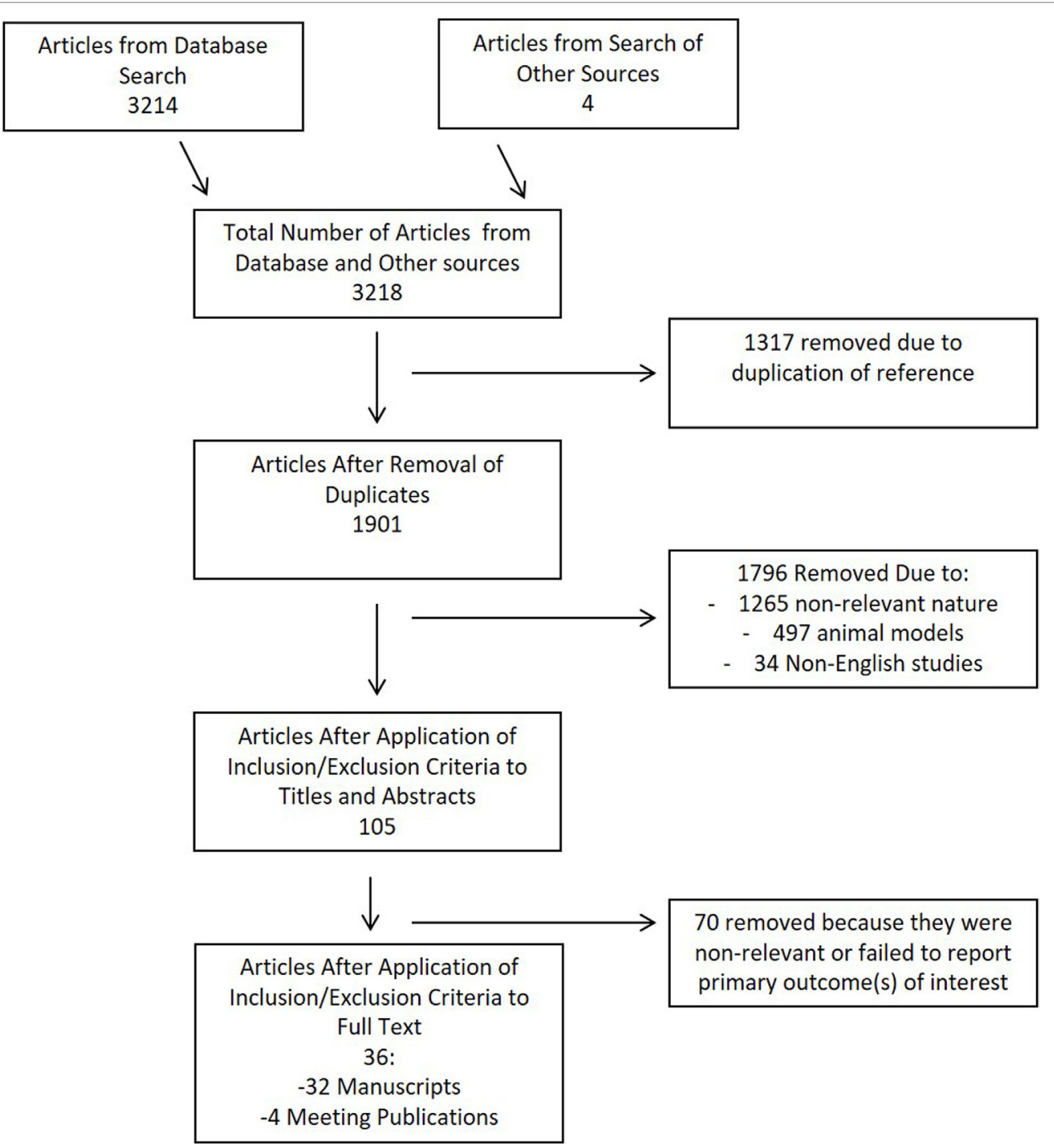

FIGURE 2 | Flow diagram of search results for cerebrospinal fluid review.

apathy at 12 months (38), TNF-a with disinhibition at 12 months (39), and sVCAM/sICAM/sFAS with depression at 6 months (40).

Neurophysiologic Outcome. Three studies discussed the correlation between CSF cytokine levels and $\operatorname{ICP/CPP~}(36,48,52)$. Elevated IL-6 and IL-8 levels were associated with increased ICP and decreased CPP in one study (52). Elevated CSF IL-1b was associated with increased ICP in two studies $(36,48)$. One study found an association between CSF IL- 6 and IL-8 levels and reduced middle cerebral artery (MCA) CBFV (51). Finally, one study found an association between IL- 6 levels and the mean change in somatosensory evoked potential over $96 \mathrm{~h}$ recording window (49).

\section{Nil Association Studies}

Our review identified 13 studies documenting a "nil association" between CSF measured cytokines in sTBI patients and various outcomes of interest (53-65). Eleven studies reported no association between various CSF cytokines and patient outcome, as reported by in-hospital mortality or GOS at 3-6 months (53-55, 58-65). The cytokines reported within these studies varied significantly, with the most common "nil associations" reported for IL-1b, IL-6, IL-8, IL-10, TNF-a, and sTNFR. A total of 376 patients were described within these studies. Two studies reported no association between CSF cytokine measures and ICP/CPP $(55,57)$, while one study failed to determine an association between CSF IL-1b and post-traumatic epilepsy (56). Further detail on the "nil association" studies can be found at the bottom of Table 4.

\section{Complications}

Within the CMD cytokine manuscripts, the majority failed to report whether complications were considered within the data collection. Only three papers disclosed complication reporting $(18,28,29)$, with two reporting "no complications" $(28,29)$, and 
one reporting a CMD catheter malfunction in one patient (19). The complication profiles may be under-reported within the CMD studies. Complication reporting within the CSF cytokine studies was essentially non-existent, with the focus of these studies the association between CSF cytokine measures and various outcomes.

\section{DISCUSSION}

\section{CMD Cytokines in sTBI}

Our scoping systematic review completed for CMD cytokine measures in sTBI allows limited conclusions. Despite 19 publications (11-29), this literature is based on very small numbers of patients with many studies conducted on the same patient populations with banked CMD samples. However, the limited conclusions are important. First, CMD-based measurement of cytokines is feasible. Second, CMD catheter location makes a difference in the levels of cytokines measured, with peri-lesional tissue producing high levels compared to distant or healthier tissue $(11,13)$. Third, peaks in CMD cytokine measures may occur within the first 48-72 h for IL-1b, IL-6, and IL-8 (21-23). Interestingly, IL-10 seems to remain elevated in CMD samples through the duration of the sampling periods described $(22,26)$. Fourth, IL-6 levels may prove to be predictive of ongoing second insults such as ischemia $(18,19)$. Fifth, the data from the rhIL1ra studies $(16,17)$ shows that subcutaneous rhIL-1ra leads to both an increase in CMD IL-1 ra and a modulation of microglial/ macrophage based cytokine profiles. Sixth, CMD IL-1b/IL-1ra/ IL-6/IL-8 may be associated with poor outcome (11, 20, 29), up to 6 months post-injury. Finally, complications related to the use of CMD catheters are likely to be under-reported.

\section{CSF Cytokines in sTBI}

Our systematic review of CSF cytokines in sTBI, focused on the association between cytokine measures and patient, tissue outcome, or neurophysiology outcomes identified some interesting trends. First, a large number of heterogeneous studies correlated CSF cytokine levels with patient outcome, defined as either mortality or GOS at 6-12 months post-injury. Various large panels of cytokines were described within these studies, but the strongest associations with outcome were found for IL-1b, IL-1ra, IL-6, IL-8, IL-10, and TNF. Most studies described an association between elevated levels of these cytokines and poor GOS/ increased mortality. Second, psychiatric outcome at 6-12 months post-injury appears to have some association to CSF cytokine levels (37-40). Elevated CSF IL-6, IL-8, and TNF seem to have the strongest associations with depression, apathy, and disinhibition at 6-12 months. Third, analysis of the impact of CSF cytokine levels on neurophysiologic measures is limited, with only five studies documenting such data $(36,48,49,51,52)$. The strongest relationship identified here was the link between elevated levels of various cytokines, such as IL- 6 or IL-1b, and elevated ICP $(36,48,52)$. Further work is required before robust conclusions can be drawn in this area. Fourth, none of the studies explored the link between CSF cytokine measures and tissue outcome, as assessed by follow-up neuroimaging. Fifth, despite the "positive" associations found in the previously described papers, 11 manuscripts found no relationship between CSF cytokines and patient outcome $(53-55,58-65)$. The patient numbers in the individual studies, which reported no associations was much smaller than that in the studies describing a positive association between CSF cytokines and patient outcome (mean of 28 vs. 41 patients/study, respectively), making lack of power a possible cause of a negative result. Further patients in the "nil association" studies represented an overall smaller sample, totaling 376 patients vs. 948 patients in the "positive association" studies. Finally, complication reporting within the CSF cytokine studies was absent. Selective reporting bias here is a major concern.

\section{Limitations}

Despite the interesting results of these two systematic reviews, there are significant study limitations, which need to be highlighted. Limitations with each separate review can be found within the subsections to follow.

\section{CMD Cytokine Review}

First, there were a small number of heterogenous studies found for the CMD review, with some manuscripts reporting on the same patient populations based on banked CMD samples. Most of these studies had patient cohort with unspecified heterogeneous patterns of injury in the setting of sTBI. The exceptions were the studies describing "diffuse" TBI patients only. These drawbacks limit the generalizability of the results to all patients with sTBI. Second, the ICU and surgical therapies received by these patients during CMD sample collection/processing was quite heterogeneous and poorly reported, and could have driven substantial variation in CMD cytokine measures. Third, there were variations in CMD catheter location between studies. This could impact the CMD cytokine measures obtained and the described relationships. Fourth, complications association with CMD monitoring was seldom reported. We believe there is significant selective harms reporting. Finally, given the studies and results identified for the CMD review, there is likely a large publication bias, favoring only studies with positive results.

\section{CSF Cytokine Review}

First, there were many quite heterogeneous studies identified in the CSF cytokine review. The included papers varied by study design, number of patients, patient inclusion criteria, ICU-based therapies offered/provided to patients, blinding during outcome assessment, and primary outcome of the studies. Information regarding the relationship between CSF cytokine measures and patient outcome was often buried within the text, and often not an explicit target for the study. Furthermore, selective outcome reporting with regards to individual CSF cytokine measures and their association to patient outcome was present in many studies. Thus, the conclusions that can be drawn from these studies and the strength of associations between CSF cytokines with patient outcome/neurophysiologic outcome are limited. Second, selective outcome reporting was an issue in many studies with preference to reporting significant association(s) only, making no reference to other CSF measures and the results of statistical analysis. Third, complication reporting was concerning within 
the literature identified (as mentioned above). Significant underreporting is suspected, with selective harms reporting the likely cause. Fourth, given all the above limitations and heterogeneity issues, a meta-analysis was not performed. Finally, though majority of studies report a positive association between cytokine levels and outcome, given that this is an emerging area of research, it is important to consider whether this might represent a publication bias toward positive studies.

\section{Correlation with Clinical Parameters}

Several studies attempt to correlate a specific mediator concentration with outcome. As these mediators are known to act in complex cascades and show a high degree of statistical collinearity, simple inferences cannot be made about the role of a given mediator in causing a particular outcome or relating to a clinical parameter such as ICP. As these mediators are induced by the initial traumatic insult, they are all confounded by severity of injury: it is, therefore, not surprising that a high concentration of cytokine relates to a worsened clinical parameter. Furthermore, the timing of monitoring in relation to the time of injury is not consistently reported. Several mediators, such as IL6, can have differing biological effects depending on the milieu in which they are produced (68). Finally, many mediators are known to act in concert and regulate the same downstream pathways (e.g., IL1b and IL1ra) such that measuring a mediator in isolation does not reflect its true biological role, which is time and milieu dependent.

\section{Future Directions}

Given the significant heterogeneity in both study design, patient injury patterns, ICU/surgical treatments, and CMD/CSF cytokine measures identified within both systematic reviews, there is substantial room for more investigation into this emerging area of the literature in sTBI.

Although it is tempting to simply suggest that larger studies are done to overcome the heterogeneity in injury patterns following TBI, there are significant limitations to this approach. There are an ever-expanding list of mediators available for analysis over multiple time points in a range of biological fluids and without a robust understanding of the interaction between these mediators, it is unlikely that a meaningful pattern will emerge through brute force of numbers. More refined approaches that explore within patient comparisons with multiple sites of monitoring (69), interventional studies in which specific modulation of a biological pathway (16), and more sophisticated multivariate statistical methods (14).

Some studies have attempted to relate intensive care parameters such as ICP to the cytokine and chemokine response to TBI (26). This is not a simple relationship as the time frame over which cytokines and chemokines are produced occur over several days and weeks, rather than over the minutes and hours. There is insufficient evidence to stipulate, which intensive care interventions should be applied during monitoring of inflammatory mediators; however, it is important for individual studies to report their intensive care protocols and interventions.

As CMD is necessarily focal in nature, strict reporting of the method of localization is required and ideally 2 catheter studies,
1 in peri-lesional tissue and 1 in healthy tissue provides the most informative data (quote consensus paper).

When multiple mediators are measured, multivariate statistical methods must be employed, such as multivariate projection methods in order to model the potential interactions $(14,70)$.

This could potentially identify cytokine patterns of coexpression in CMD and CSF, highlighting target for future studies and therapeutic targets.

One deficit in the current CMD literature is complication reporting. In part, this relates to the difficulty in apportioning complications to CMD catheter insertion specifically. As patients will have invasive monitoring for ICP monitoring and brain tissue oxygenation in any circumstance for directing clinical therapy, the additional risk of inserting CMD through an existing cranial access device is small and difficult to quantify. Nevertheless, transparency dictates that complications are reported. Standardization of the methodologies employed allows multicenter prospective evaluation of cytokines within CDM and $\mathrm{CSF}$ and is necessary to improve patient recruitment and aid with spreading the substantial cost of cytokine analysis among centers. Without this collaboration, the limitations with single center recruitment and costs of cytokine processing in CMD and CSF limits the ability to combine datasets across units and studies. This would allow easier compilation of data sets and may add clarity to the associations highlighted within this manuscript. Finally, a consideration of the methodological factors that determine microdialysis catheter efficiency, including choice of perfusion fluid, catheter membrane, and pump flow rate all have an impact on the result obtained.

\section{CONCLUSION}

The evaluation of CMD and CSF cytokines is an emerging area of the literature in sTBI. The two scoping systematic reviews have demonstrated a limited literature available on CMD cytokine measurement in sTBI, with some preliminary data supporting feasibility of measurement and associations between cytokines and patient outcome. Second, a number CSF cytokine levels may be associated with patient outcome at 6-12 months, including IL-1b, IL-1ra, IL-6, IL-8, IL-10, and TNF. Third, there is little to no literature to date in support of an association between CSF cytokines and neurophysiologic or tissue outcomes. Ultimately, the aim of CMD monitoring of inflammatory mediators is to reveal the underlying pathophysiology of TBI rather than as a clinical tool.

\section{AUTHOR CONTRIBUTIONS}

FZ was involved in project conception, design, systematic review searching, data extraction/tabulation, data interpretation, manuscript composition, and editing. ET was involved with data extraction/tabulation, manuscript composition, and editing. MC was involved in manuscript composition and editing. $\mathrm{PH}$ was involved in design, data interpretation, and manuscript editing. $\mathrm{DM}$ and $\mathrm{AH}$ was involved in design, data interpretation, manuscript writing, and editing. 


\section{FUNDING}

This work was made possible through salary support through: the Cambridge Commonwealth Trust Scholarship, the Royal College of Surgeons of Canada-Harry S. Morton Traveling Fellowship in Surgery, the University of Manitoba Clinician Investigator Program, R. Samuel McLaughlin Research and Education Award, the Manitoba Medical Service Foundation, and the University of Manitoba Faculty of Medicine Dean's Fellowship Fund. These studies were supported by National Institute for Healthcare Research (NIHR, UK) through the Acute Brain Injury and Repair theme of the Cambridge NIHR Biomedical Research Center, an NIHR Senior Investigator Award to DM,

\section{REFERENCES}

1. Corps KN, Roth TL, McGavern DB. Inflammation and neuroprotection in traumatic brain injury. JAMA Neurol (2015) 72(3):355-62. doi:10.1001/ jamaneurol.2014.3558

2. Kumar A, Loane DJ. Neuroinflammation after traumatic brain injury: opportunities for therapeutic intervention. Brain Behav Immun (2012) 26(8): 1191-201. doi:10.1016/j.bbi.2012.06.008

3. Logan A, Frautschy SA, Gonzalez AM, Sporn MB, Baird A. Enhanced expression of transforming growth factor beta 1 in the rat brain after a localized cerebral injury. Brain Res (1992) 587(2):216-25. doi:10.1016/ 0006-8993(92)91000-5

4. Xiong XX, Gu LJ, Shen J, Kang XH, Zheng YY, Yue SB, et al. Probenecid protects against transient focal cerebral ischemic injury by inhibiting HMGB1 release and attenuating AQP4 expression in mice. Neurochem Res (2014) 39(1):216-24. doi:10.1007/s11064-013-1212-z

5. Mukandala G, Tynan R, Lanigan S, O'Connor JJ. The effects of hypoxia and inflammation on synaptic signaling in the CNS. Brain Sci (2016) 6(1):E6. doi:10.3390/brainsci6010006

6. Luheshi NM, Kovács KJ, Lopez-Castejon G, Brough D, Denes A. Interleukin$1 \alpha$ expression precedes IL- $1 \beta$ after ischemic brain injury and is localised to areas of focal neuronal loss and penumbral tissues. J Neuroinflammation (2011) 8:186. doi:10.1186/1742-2094-8-186

7. Plesnila N. The immune system in traumatic brain injury. Curr Opin Pharmacol (2016) 26:110-7. doi:10.1016/j.coph.2015.10.008

8. Gyoneva S, Ransohoff RM. Inflammatory reaction after traumatic brain injury: therapeutic potential of targeting cell-cell communication by chemokines. Trends Pharmacol Sci (2015) 36(7):471-80. doi:10.1016/j.tips.2015. 04.003

9. Sordillo PP, Sordillo LA, Helson L. Bifunctional role of pro-inflammatory cytokines after traumatic brain injury. Brain Inj (2016) 30(9):1043-53. doi:10.3109/02699052.2016.1163618

10. Di Battista AP, Rhind SG, Hutchison MG, Hassan S, Shiu MY, Inaba K, et al. Inflammatory cytokine and chemokine profiles are associated with patient outcome and the hyperadrenergic state following acute brain injury. J Neuroinflammation (2016) 13:40. doi:10.1186/s12974-016-0500-3

11. Cederberg D, Figaji A, Siesjo P. Cytokine analysis in paediatric severe traumatic brain injury. Brain Inj (2012) 26(4-5):719-20.

12. Figaji A, Ross S, Rohlwink U, Fieggen G, Padayachy L, Hoffman J. Metabolic and inflammatory changes in the injured brain. Childs Nerv Syst (2013) 29(9):1718-9.

13. Guilfoyle MR, Helmy A, Carpenter KLH, Hutchinson PJ. Localised cytokine responses in peri-contusional brain following traumatic injury - a paired microdialysis study. Br J Neurosurg (2015) 29(4):452.

14. Helmy A, Antoniades CA, Guilfoyle MR, Carpenter KL, Hutchinson PJ. Principal component analysis of the cytokine and chemokine response to human traumatic brain injury. PLoS One (2012) 7(6):e39677. doi:10.1371/ journal.pone.0039677

15. Helmy A, Carpenter KL, Menon DK, Pickard JD, Hutchinson PJ. The cytokine response to human traumatic brain injury: temporal profiles and evidence and an NIHR Research Professorship to PH. Authors were also supported by a European Union Framework Program 7 grant (CENTER-TBI; Grant Agreement No. 602150). ET has received funding support from Swedish Society of Medicine (Grant no. SLS-587221). AH is supported by an MRC Studentship for Neuro-inflammation following Human Traumatic Brain injury (G0802251).

\section{SUPPLEMENTARY MATERIAL}

The Supplementary Material for this article can be found online at http://journal.frontiersin.org/article/10.3389/fneur.2017.00331/ full\#supplementary-material.

for cerebral parenchymal production. J Cereb Blood Flow Metab (2011) 31(2):658-70. doi:10.1038/jcbfm.2010.142

16. Helmy A, Guilfoyle MR, Carpenter KL, Pickard JD, Menon DK, Hutchinson PJ. Recombinant human interleukin-1 receptor antagonist in severe traumatic brain injury: a phase II randomized control trial. J Cereb Blood Flow Metab (2014) 34(5):845-51. doi:10.1038/jcbfm.2014.23

17. Helmy A, Guilfoyle MR, Carpenter KL, Pickard JD, Menon DK, Hutchinson PJ. Recombinant human interleukin-1 receptor antagonist promotes M1 microglia biased cytokines and chemokines following human traumatic brain injury. J Cereb Blood Flow Metab (2016) 36(8):1434-48. doi:10.1177/0271678X15620204

18. Hillman J, Aneman O, Andersen C, Sjogren F, Saberg C, Mellergard P. A microdialysis technique for routine measurement of macromolecules in the injured human brain. Neurosurgery (2005) 56(6):1264-8. doi:10.1227/01. NEU.0000159711.93592.8D

19. Hillman J, Aneman O, Persson M, Andersson C, Dabrosin C, Mellergard P. Variations in the response of interleukins in neurosurgical intensive care patients monitored using intracerebral microdialysis. JNeurosurg (2007) 106(5):820-5. doi:10.3171/jns.2007.106.5.820

20. Hutchinson PJ, O'Connell MT, Rothwell NJ, Hopkins SJ, Nortje J, Carpenter KL, et al. Inflammation in human brain injury: intracerebral concentrations of IL-1alpha, IL-1beta, and their endogenous inhibitor IL-1ra. J Neurotrauma (2007) 24(10):1545-57. doi:10.1089/neu.2007.0295

21. Mellergard P, Aneman O, Sjoegren F, Pettersson P, Hillman J. Changes in extracellular concentrations of some cytokines, chemokines, and eurotrophic factors after insertion of intracerebral microdialysis catheters in neurosurgical patients. Neurosurgery (2008) 62(1):151-7. doi:10.1227/01.NEU. 0000311072.33615.3A

22. Mellergard P, Aneman O, Sjogren F, Saberg C, Hillman J. Differences in cerebral extracellular response of interleukin-1 beta, interleukin-6, and interleukin-10 after subarachnoid hemorrhage or severe head trauma in humans. Neurosurgery (2011) 68(1):12-9. doi:10.1227/NEU. 0b013e3181ef2a40

23. Mellergard P, Sjogren F, Hillman J. Release of VEGF and FGF in the extracellular space following severe subarachnoidal haemorrhage or traumatic head injury in humans. Br J Neurosurg (2010) 24(3):261-7. doi:10.3109/ 02688690903521605

24. Mellergard P, Sjogren F, Hillman J. The cerebral extracellular release of glycerol, glutamate, and FGF2 is increased in older patients following severe traumatic brain injury. J Neurotrauma (2012) 29(1):112-8. doi:10.1089/neu. 2010.1732

25. Mondello S, Jeromin A, Bullock R, Sweaney JM, Streeter J, Schmid K, et al. In vivo monitoring of cytokines and brain biomarker damage following severe traumatic brain injury: a microdialysis study. J Neurotrauma (2011) 28(6):A84.

26. Perez-Barcena J, Ibanez J, Brell M, Crespi C, Frontera G, Llompart-Pou JA, et al. Lack of correlation among intracerebral cytokines, intracranial pressure, and brain tissue oxygenation in patients with traumatic brain injury and diffuse lesions. Crit Care Med (2011) 39(3):533-40. doi:10.1097/CCM. $0 \mathrm{~b} 013 \mathrm{e} 318205 \mathrm{c} 7 \mathrm{a} 4$ 
27. Roberts DJ, Jenne CN, Léger C, Kramer AH, Gallagher CN, Todd S, et al. Association between the cerebral inflammatory and matrix metalloproteinase responses after severe traumatic brain injury in humans. J Neurotrauma (2013) 30(20):1727-36. doi:10.1089/neu.2012.2842

28. Winter CD, Iannotti F, Pringle AK, Trikkas C, Clough GF, Church MK. A microdialysis method for the recovery of IL-1beta, IL- 6 and nerve growth factor from human brain in vivo. J Neurosci Methods (2002) 119(1):45-50. doi:10.1016/S0165-0270(02)00153-X

29. Winter CD, Pringle AK, Clough GF, Church MK. Raised parenchymal interleukin-6 levels correlate with improved outcome after traumatic brain injury. Brain (2004) 127(2):315-20. doi:10.1093/brain/awh039

30. Abboud A, Mi Q, Puccio A, Okonkwo D, Buliga M, Constantine G, et al. Inflammation following traumatic brain injury in humans: insights from data-driven and mechanistic models into survival and death. Front Pharmacol (2016) 7:342. doi:10.3389/fphar.2016.00342

31. Bell MJ, Kochanek PM, Doughty LA, Carcillo JA, Adelson PD, Clark RS, et al. Interleukin-6 and interleukin-10 in cerebrospinal fluid after severe traumatic brain injury in children. J Neurotrauma (1997) 14(7):451-7. doi:10.1089/neu.1997.14.451

32. Chiaretti A, Antonelli A, Mastrangelo A, Pezzotti P, Tortorolo L, Tosi F, et al. Interleukin-6 and nerve growth factor upregulation correlates with improved outcome in children with severe traumatic brain injury. J Neurotrauma (2008) 25(3):225-34. doi:10.1089/neu.2007.0405

33. Chiaretti A, Antonelli A, Riccardi R, Genovese O, Pezzotti P, Di Rocco C, et al. Nerve growth factor expression correlates with severity and outcome of traumatic brain injury in children. Eur J Paediatr Neurol (2008) 12(3):195-204. doi:10.1016/j.ejpn.2007.07.016

34. Chiaretti A, Genovese O, Aloe L, Antonelli A, Piastra M, Polidori G, et al. Interleukin 1beta and interleukin 6 relationship with paediatric head trauma severity and outcome. Childs Nerv Syst (2005) 21(3):185-93. doi:10.1007/ s00381-004-1032-1

35. Hans VH, Kossmann T, Joller H, Otto V, Morganti-Kossmann MC. Interleukin-6 and its soluble receptor in serum and cerebrospinal fluid after cerebral trauma. Neuroreport (1999) 10(2):409-12. doi:10.1097/00001756-19990205000036

36. Hayakata T, Shiozaki T, Tasaki O, Ikegawa H, Inoue Y, Toshiyuki F, et al. Changes in CSF S100B and cytokine concentrations in early-phase severe traumatic brain injury. Shock (2004) 22(2):102-7. doi:10.1097/01. shk.0000131193.80038.f1

37. Jamil N, Failla M, Boles JA, Goyal A, Wagner A. Acute inflammatory cytokine profiles predict depression following severe TBI. JNeurotrauma (2013) 30(15):A6.

38. Juengst SB, Arenth PM, Wagner A. Inflammation and apathy associations in the first year after traumatic brain injury. Arch Phys Med Rehabil (2015) 96(10):e98-9. doi:10.1016/j.apmr.2015.08.330

39. Juengst SB, Kumar RG, Arenth PM, Wagner AK. Exploratory associations with Tumor Necrosis Factor-alpha, disinhibition and suicidal endorsement after traumatic brain injury. Brain Behav Immun (2014) 41(1):134-43. doi:10.1016/j.bbi.2014.05.020

40. Juengst SB, Kumar RG, Failla MD, Goyal A, Wagner AK. Acute inflammatory biomarker profiles predict depression risk following moderate to severe traumatic brain injury. J Head Trauma Rehabil (2015) 30(3):207-18. doi:10.1097/ HTR.0000000000000031

41. Kirchhoff C, Buhmann S, Bogner V, Stegmaier J, Leidel BA, Braunstein V, et al. Cerebrospinal IL-10 concentration is elevated in non-survivors as compared to survivors after severe traumatic brain injury. Eur J Med Res (2008) 13(10):464-8.

42. Kossmann T, Hans V, Imhof HG, Trentz O, Morganti-Kossmann MC. Interleukin-6 released in human cerebrospinal fluid following traumatic brain injury may trigger nerve growth factor production in astrocytes. Brain Res (1996) 713(1-2):143-52. doi:10.1016/0006-8993(95)01501-9

43. Kumar RG, Diamond ML, Boles JA, Berger RP, Tisherman SA, Kochanek PM, et al. Acute CSF interleukin-6 trajectories after TBI: associations with neuroinflammation, polytrauma, and outcome. Brain Behav Immun (2015) 45:253-62. doi:10.1016/j.bbi.2014.12.021

44. Kumar RG, Rubin JE, Berger RP, Kochanek PM, Wagner AK. Principal components derived from CSF inflammatory profiles predict outcome in survivors after severe traumatic brain injury. Brain Behav Immun (2016) 53:183-93. doi:10.1016/j.bbi.2015.12.008
45. Kushi H, Saito T, Makino K, Hayashi N. IL-8 is a key mediator of neuroinflammation in severe traumatic brain injuries. Acta Neurochir Suppl (2003) 86:347-50.

46. Nwachuku EL, Puccio AM, Adeboye A, Chang YF, Kim J, Okonkwo DO. Time course of cerebrospinal fluid inflammatory biomarkers and relationship to 6-month neurologic outcome in adult severe traumatic brain injury. Clin Neurol Neurosurg (2016) 149:1-5. doi:10.1016/j.clineuro.2016.06.009

47. Santarsieri M, Kumar RG, Kochanek PM, Berga S, Wagner AK. Variable neuroendocrine-immune dysfunction in individuals with unfavorable outcome after severe traumatic brain injury. Brain Behav Immun (2015) 45:15-27. doi:10.1016/j.bbi.2014.09.003

48. Shiozaki T, Hayakata T, Tasaki O, Hosotubo H, Fuijita K, Mouri T, et al. Cerebrospinal fluid concentrations of anti-inflammatory mediators in early-phase severe traumatic brain injury. Shock (2005) 23(5):406-10. doi:10.1097/01.shk.0000161385.62758.24

49. Singhal A, Baker AJ, Hare GM, Reinders FX, Schlichter LC, Moulton RJ. Association between cerebrospinal fluid interleukin-6 concentrations and outcome after severe human traumatic brain injury. J Neurotrauma (2002) 19(8):929-37. doi:10.1089/089771502320317087

50. Whalen MJ, Carlos TM, Kochanek PM, Wisniewski SR, Bell MJ, Clark RS, et al. Interleukin-8 is increased in cerebrospinal fluid of children with severe head injury. Crit Care Med (2000) 28(4):929-34. doi:10.1097/00003246-200004000-00003

51. Muller M, Schwerdtfeger K, Maier B, Mautes A, Schiedat T, Bianchi O, et al. Cerebral blood flow velocity and inflammatory response after severe traumatic brain injury. Eur J Ultrasound (2001) 12(3):203-8. doi:10.1016/ S0929-8266(00)00118-X

52. Stein DM, Lindell A, Murdock KR, Kufera JA, Menaker J, Keledjian K, et al. Relationship of serum and cerebrospinal fluid biomarkers with intracranial hypertension and cerebral hypoperfusion after severe traumatic brain injury. J Trauma (2011) 70(5):1096-103. doi:10.1097/TA. 0b013e318216930d

53. Amick JE, Yandora KA, Bell MJ, Wisniewski SR, Adelson PD, Carcillo JA, et al. The Th1 versus Th2 cytokine profile in cerebrospinal fluid after severe traumatic brain injury in infants and children. Pediatr Crit Care Med (2001) 2(3):260-4. doi:10.1097/00130478-200107000-00013

54. Buttram SD, Wisniewski SR, Jackson EK, Adelson PD, Feldman K, Bayir $\mathrm{H}$, et al. Multiplex assessment of cytokine and chemokine levels in cerebrospinal fluid following severe pediatric traumatic brain injury: effects of moderate hypothermia. J Neurotrauma (2007) 24(11):1707-17. doi:10.1089/ neu.2007.0349

55. Csuka E, Morganti-Kossmann MC, Lenzlinger PM, Joller H, Trentz O, Kossmann T. IL-10 levels in cerebrospinal fluid and serum of patients with severe traumatic brain injury: relationship to IL-6, TNF-alpha, TGF-beta1 and blood-brain barrier function. J Neuroimmunol (1999) 101(2):211-21. doi:10.1016/S0165-5728(99)00148-4

56. Diamond ML, Ritter AC, Failla MD, Boles JA, Conley YP, Kochanek PM, et al. IL-1beta associations with posttraumatic epilepsy development: a genetics and biomarker cohort study. Epilepsia (2014) 55(7):1109-19. doi:10.1111/ epi.12714

57. Goodman JC, Van M, Gopinath SP, Robertson CS. Pro-inflammatory and pro-apoptotic elements of the neuroinflammatory response are activated in traumatic brain injury. Acta Neurochir Suppl (2008) 102:437-9. doi:10.1007/978-3-211-85578-2_85

58. Gopcevic A, Mazul-Sunko B, Marout J, Sekulic A, Antoljak N, Siranovic M, et al. Plasma interleukin-8 as a potential predictor of mortality in adult patients with severe traumatic brain injury. Tohoku J Exp Med (2007) 211(4):387-93. doi:10.1620/tjem.211.387

59. Lenzlinger PM, Hans VH, Joller-Jemelka HI, Trentz O, MorgantiKossmann MC, Kossmann T. Markers for cell-mediated immune response are elevated in cerebrospinal fluid and serum after severe traumatic brain injury in humans. J Neurotrauma (2001) 18(5):479-89. doi:10.1089/ 089771501300227288

60. Maier B, Lehnert M, Laurer HL, Mautes AE, Steudel WI, Marzi I. Delayed elevation of soluble tumor necrosis factor receptors p75 and p55 in cerebrospinal fluid and plasma after traumatic brain injury. Shock (2006) 26(2):122-7. doi:10.1097/01.shk.0000223127.41641.f4

61. Maier B, Schwerdtfeger K, Mautes A, Holanda M, Muller M, Steudel WI, et al. Differential release of interleukines 6, 8, and 10 in cerebrospinal 
fluid and plasma after traumatic brain injury. Shock (2001) 15(6):421-6. doi:10.1097/00024382-200115060-00002

62. Morganti-Kossmann C, Bye N, Nguyen P, Kossmann T, Rosenfeld J, Yan E. Cytokines and brain injury markers in TBI patients: differences in focal and diffuse brain damage, and normoxic or hypoxic status and their relation to neurological outcome. J Neurotrauma (2012) 29(10):A188.

63. Newell E, Shellington DK, Simon DW, Bell MJ, Kochanek PM, Feldman K, et al. Cerebrospinal fluid markers of macrophage and lymphocyte activation after traumatic brain injury in children. Pediatr Crit Care Med (2015) 16(6):549-57. doi:10.1097/PCC.0000000000000400

64. Ross SA, Halliday MI, Campbell GC, Brynes DP, Rowlands BJ. The presence of tumour necrosis factor in CSF and plasma after severe head injury. $\mathrm{Br}$ J Neurosurg (1994) 8(4):419-25. doi:10.3109/02688699408995109

65. Uzan M, Tanriover N, Bozkus H, Gumustas K, Guzel O, Kuday C. Nitric Oxide (NO) metabolism in the cerebrospinal fluid of patients with severe head injury: inflammation as a possible cause of elevated no metabolites. Surg Neurol (2001) 56(6):350-6. doi:10.1016/S0090-3019(01)00633-4

66. Higgins JPT, Green S, editors. Cochrane Handbook for Systematic Reviews of Interventions Version 5.1.0. (2013). Available from: http:handbook. cochrane.org

67. Moher D, Liberati A, Tetzlaff J, Altman DG; PRISMA Group. Preferred reporting items for systematic reviews and meta-analysis: the PRISMA statement. Ann Intern Med (2009) 151(4):264-9. doi:10.7326/0003-4819151-4-200908180-00135

68. Simon DW, McGeachy MJ, Bayır H, Clark RS, Loane DJ, Kochanek PM. The far-reaching scope of neuroinflammation after traumatic brain injury. Nat Rev Neurol (2017) 13(3):171-91. doi:10.1038/nrneurol.2017.13

69. Guilfoyle MR, Carpenter KL, Helmy A, Pickard JD, Menon DK, Hutchinson PJ. Matrix metalloproteinase expression in contusional traumatic brain injury: a paired microdialysis study. J Neurotrauma (2015) 32(20):1553-9. doi:10.1089/neu.2014.3764
70. Helmy A, De Simoni MG, Guilfoyle MR, Carpenter KL, Hutchinson PJ. Cytokines and innate inflammation in the pathogenesis of human traumatic brain injury. Prog Neurobiol (2011) 95(3):352-72. doi:10.1016/j.pneurobio. 2011.09 .003

Conflict of Interest Statement: FZ has received salary support for dedicated research time, during which this project was partially completed. Such salary support came from: the Cambridge Commonwealth Trust Scholarship, the Royal College of Surgeons of Canada-Harry S. Morton Traveling Fellowship in Surgery, the University of Manitoba Clinician Investigator Program, R. Samuel McLaughlin Research and Education Award, the Manitoba Medical Service Foundation, and the University of Manitoba-Faculty of Medicine Dean's Fellowship Fund. ET has received funding support from Swedish Society of Medicine (Grant no. SLS587221). MC has financial interest in a part of licensing fee for ICM+ software (Cambridge Enterprise Ltd., UK). Unpaid co-director of Technicam Ltd.-producer of Cranial Access Device used for CMD insertion. PH is the director of Technicam manufacturer of the Technicam Cranial Access Device. DM has consultancy agreements and/or research collaborations with GlaxoSmithKline Ltd.; Ornim Medical; Shire Medical Ltd.; Calico Inc.; Pfizer Ltd.; Pressura Ltd.; Glide Pharma Ltd.; and NeuroTraumaSciences LLC.

The reviewer, FC, and handling editor declared their shared affiliation, and the handling editor states that the process met the standards of a fair and objective review.

Copyright $\odot 2017$ Zeiler, Thelin, Czosnyka, Hutchinson, Menon and Helmy. This is an open-access article distributed under the terms of the Creative Commons Attribution License (CC BY). The use, distribution or reproduction in other forums is permitted, provided the original author(s) or licensor are credited and that the original publication in this journal is cited, in accordance with accepted academic practice. No use, distribution or reproduction is permitted which does not comply with these terms. 